\begin{tabular}{|c|l|}
\hline Title & Large eddy simulation on the unsteady aerodynamic response of a road vehicle in transient crosswinds \\
\hline Author(s) & Tsubokura, Makoto; Nakashima, Takuji; Kitay ama, Masashi; Ikawa, Y uki; Doh, Deog Hee; Kobay ashi, Toshio \\
\hline Citation & $\begin{array}{l}\text { International Journal of Heat and Fluid Flow,31(6), 1075-1086 } \\
\text { https://doi.org/10.1016/.ijheatfluidflow.2010.05.008 }\end{array}$ \\
\hline Issue Date & 2010 -12 \\
\hline Doc URL & http://hdl.handle.net/2115/49221 \\
\hline Type & article (author version) \\
\hline File Information & IJHFF31-6_1075-1086.pdf \\
\hline
\end{tabular}

Instructions for use 


\title{
Large Eddy Simulation on the Unsteady Aerodynamic Response of a Road Vehicle in Transient Crosswinds
}

\author{
Makoto Tsubokura ${ }^{1 *}$ \\ Takuji Nakashima $^{2}$ \\ Masashi Kitayama ${ }^{3}$ \\ Yuki Ikawa ${ }^{1}$ \\ Deog Hee Doh ${ }^{4}$ \\ Toshio Kobayashi $^{5}$ \\ *Corresponding author
}

${ }^{1}$ Division of Mechanical and Space Engineering, Graduate School of Engineering, Hokkaido University

N13, W8, Kita-ku, Sapporo, Hokkaido, 060-8628, Japan

Tel: (+81)-11-706-6723, fax: (+81)-11-706-6723

mtsubo@eng.hokudai.ac.jp

${ }^{2}$ Department of Social and Environmental Engineering, Graduate School of Engineering, Hiroshima University

1-4-1 Kagamiyama, Higashi Hiroshima, 739-8527, Japan

${ }^{3}$ Subaru Engineering Division, Fuji Heavy Industries Ltd.

1-1 Subaru-cho, Ota, Gunma, 373-8555, Japan

${ }^{4}$ Division of Mechanical and Information Engineering, Korea Maritime University

1 Dongsam-dong, Yeongdo-gu, Busan, 606-791, Korea

${ }^{5}$ Japan Automobile Research Institute

1-30 Shibadaimon, Minato-ku, Tokyo, 105-0012, Japan 


\begin{abstract}
A large eddy simulation method based on a fully unstructured finite volume method was developed, and the unsteady aerodynamic response of a road vehicle subjected to transient crosswinds was investigated. First, the method was validated for a $1 / 20$-scale wind-tunnel model in a static aerodynamic condition; this showed that the surface pressure distributions as well as the aerodynamic forces and moments were in good agreement with wind-tunnel data. Second, the method was applied to two transient crosswind situations: a sinusoidal perturbation representing the typical length scale of atmospheric turbulence and a stepwise crosswind velocity corresponding to wind gusts. Typical transient responses of the aerodynamic forces and moments such as phase shifting and undershooting or overshooting were observed, and their dependence on the frequency and amplitude of the input perturbation is discussed. Thus, the utility and validity of the large eddy simulation was demonstrated in the context that such transient aerodynamic forces are difficult to measure using a conventional wind tunnel.
\end{abstract}

Keywords: Aerodynamics, Automobile, Road Vehicle, Wind, Large Eddy Simulation (LES), Computational Fluid Dynamics (CFD) 
Nomenclature

A amplitude of the sinusoidal crosswind velocity [m]

$A_{s} \quad$ frontal area of the vehicle $\left[\mathrm{m}^{2}\right]$

$C_{D} \quad$ drag coefficient $\left(=2 F_{x} / \rho V_{0}^{2} A_{s}\right)$

$C_{L} \quad$ lift coefficient $\left(=2 F_{z} / \rho V_{0}^{2} A_{s}\right)$

$C_{S} \quad$ side force coefficient $\left(=2 F_{y} / \rho V_{0}^{2} A_{s}\right)$

$C_{M} \quad$ pitching moment coefficient $\left(=2 M_{y} / \rho V_{0}^{2} A_{s} L\right)$

$C_{N} \quad$ yawing moment coefficient $\left(=2 M_{z} / \rho V_{0}^{2} A_{s} L\right)$

$f \quad$ frequency of the crosswind $[\mathrm{Hz}]$

$f_{d} \quad$ van Driest type damping function

$F_{x} \quad$ drag force $[\mathrm{N}]$

$F_{y} \quad$ side force $[\mathrm{N}]$

$F_{z} \quad$ lift force $[\mathrm{N}]$

$H \quad$ height of the vehicle [m]

$L \quad$ length of the vehicle [m]

$M_{x} \quad$ roll moment $[\mathrm{Nm}]$

$M_{y} \quad$ pitch moment $[\mathrm{Nm}]$

$M_{z} \quad$ yaw moment $[\mathrm{Nm}]$

$S_{t} \quad$ Strauhal number $\left(=f L / U_{0}\right)$

$u_{i} \quad$ velocity for $i$ direction $[\mathrm{m} / \mathrm{s}]$

$U_{0} \quad$ main inlet velocity $[\mathrm{m} / \mathrm{s}]$

$v \quad$ transversal (crosswind) velocity $[\mathrm{m} / \mathrm{s}]$

$V_{0} \quad$ relative flow velocity acting on the vehicle $[\mathrm{m} / \mathrm{s}]\left(=\left(U_{0}^{2}+v^{2}\right)^{1 / 2}\right)$

$W \quad$ width of the vehicle [m]

$\beta \quad$ yaw angle of the vehicle with respect to the relative flow velocity $\left[{ }^{\circ}\right]$

$\lambda \quad$ wavelength of sinusoidal crosswind velocity [m]

$v \quad$ kinetic viscosity $\left[\mathrm{m}^{2} / \mathrm{s}\right]$

$\rho \quad$ density of the incoming fluid $\left[\mathrm{kg} / \mathrm{m}^{3}\right]$

Subscripts and superscripts

$x, y, z \quad$ main streamwise, transversal, vertical

$1,2,3$ main streamwise, transversal, vertical

$+\quad$ wall unit normalized by the kinetic viscosity and surface friction 


\section{Introduction}

In the automotive industry, the aerodynamic performance of road vehicles has mainly been evaluated by using aerodynamic coefficients such as $C_{D}, C_{L}$ or $C_{M}$, which have been utilized to improve fuel consumption or estimate vehicle maneuverability, and so on. In that context, these aerodynamic coefficients have been obtained in a static condition, in which a target vehicle is mounted on the floor of a wind tunnel with inlet flows that are uniform and smooth. However, considering that the real atmospheric wind to which a vehicle is subjected during on-road driving is fully turbulent (e.g., Cooper and Watkins, 2007), it is reasonable to suggest that discrepancies in the aerodynamic coefficients could appear between the cases with fully static and turbulent flows. The conventional method to handle the vehicle's continuous relative yaw-angle change versus the incoming flow caused by fluctuating wind is to take into account the dependence of the aerodynamic coefficients on the fixed yaw angle under the quasi-steady assumption (Cooper and Campbell, 1983). Thus, the aerodynamic coefficients are usually measured by rotating the vehicle over a range of yaw angles in a wind tunnel. The problem with the quasi-steady assumption is that it treats only relatively low-frequency responses, so it is impossible to consider the effects of a dominant turbulence mode. Concerning the turbulence mode, Cogotti (2003) developed and installed a turbulence generation system in a full-scale wind tunnel and measured the drag and lift in an ambient turbulence condition (Cogotti, 2004). The mean $C_{D}$ and front $C_{L}$ were reported to increase compared with the case without ambient turbulence.

In addition to $C_{D}, C_{L}$, and $C_{M}$ for the estimation of fuel consumption and maneuverability, $C_{S}$ and $C_{N}$ are indispensable for estimating and achieving safety in a gusty crosswind. The conventional method of assessing crosswind safety is also based on a quasi-steady analysis using averaged aerodynamic coefficients as a function of the yaw angle measured in a wind tunnel. However, the limitation of the quasi-steady analysis was revealed by Beauvais (1967), who demonstrated that $C_{N}$ seriously overshoots just after a vehicle is subjected to a wind gust and then decreases to a steady-state value. Dominy and Ryan (1999), from the same viewpoint, developed crosswind active shutters mounted on the side of the test section of a wind tunnel and measured the transient surface pressure distributions.

Even though many studies on the unsteady aerodynamic response caused by ambient turbulence and wind gusts have recently been conducted using innovative experimental setups, only limited knowledge has been acquired owing to the difficulty of capturing the unsteady aerodynamic forces and the restricted physical values to be measured. In addition, additional experimental setups for unsteady aerodynamics analyses are costly and unsuitable for the industrial development process.

Computational fluid dynamics (CFD) is an attractive approach for such problems as it can provide a large amount of transient data and detailed three-dimensional information about the flow field (e.g., Okumura and Kuriyama, 1997; Guilmineau and Chometon, 2008; Hemida and Krajnović, 2009), which can help to elucidate the comprehensive mechanisms of the unsteady aerodynamics of road vehicles. However, the conventional Reynolds-averaged Navier-Stokes (RANS) simulation is not suitable for transient analysis, especially in the case where the fluctuating incoming flow interacts with the vehicle's wake turbulence. In fact, even for the simplified vehicle called the Ahmed reference model (Ahmed and Ramm, 1984), the wake flow is fully unsteady and three-dimensional and exhibits separation at the roof's trailing edge and reattachment depending on the vehicle's rear slant angle. The recirculation bubbles above the slant deck and their interaction with the wake vortices produce large elongated trailing vortices, causing a high induced drag. Reproduction of these complicated unsteady flows is indeed challenging for turbulence simulations, and only limited success has been achieved so far using RANS approaches (e.g., Guilmineau, 2008). 
A promising candidate for this purpose is large eddy simulation (LES), in which larger eddies are solved directly while smaller and universal eddies are only modeled. Thus, the physical mechanism of the transient aerodynamic response caused by unsteady three-dimensional eddies can be explained by means of the method. Therefore, the objective of the present study is to develop a numerical method based on LES and to study the transient aerodynamic response caused by ambient turbulence and wind gusts. Recently, some attempts have been made to apply LES to the Ahmed flow (e.g., Krajnović and Davidson, 2005ab). Fares (2006) chose to use the lattice Boltzmann method instead of the spatially filtered Navier-Stokes approach and demonstrated the validity of the unsteady flow simulation. Minguez et al. (2008) proposed a high-order LES based on a multi-domain spectral Chebyshev-Fourier approach. In this study, we focus on a real production vehicle as a typical engineering application. The difficulty of the target lies in the fact that owing to the complicated geometry compared with the Ahmed model, only a limited numerical approach such as a fully unstructured finite volume/element or voxel mesh can be applied. In the present study, we used the fully unstructured finite volume method.

The ambient turbulence was simplified to a sinusoidal transversal velocity imposed on the main inlet, and, as a result, the relative yaw angle $\beta$ with respect to the incoming flow changed transiently. In the same way, the crosswind gust was represented by the simple stepwise transversal velocity imposed on the main flow.

\section{Numerical Methods}

\subsection{Governing Equations}

An incompressible Newtonian fluid was assumed, and the continuity and momentum equations were spatially filtered to obtain the governing equations of LES:

$$
\begin{aligned}
& \frac{\partial \bar{u}_{i}}{\partial x_{i}}=0 \\
& \frac{\partial \bar{u}_{i}}{\partial t}+\frac{\partial \bar{u}_{i} \bar{u}_{j}}{\partial x_{j}}=-\frac{\partial \bar{P}}{\partial x_{i}}+2 \frac{\partial}{\partial x_{j}}\left(\nu+\nu_{s g s}\right) \bar{S}_{i j} .
\end{aligned}
$$

The bar over the physical quantity indicates the spatial filtering operation for LES. The filtered strain rate tensor $\bar{S}_{i j}$ and pressure $\bar{P}$ in Eq. (2) are expressed as

$$
\begin{aligned}
& \bar{S}_{i j}=\frac{1}{2}\left(\frac{\partial \bar{u}_{j}}{\partial x_{i}}+\frac{\partial \bar{u}_{i}}{\partial x_{j}}\right), \\
& \bar{P}=\bar{p} / \rho+\left(\overline{u_{i} u_{j}}-\bar{u}_{i} \bar{u}_{j}\right) / 3 .
\end{aligned}
$$

In Eq. (2), the last term on the right represents the effect of subgrid-scale (SGS) turbulence, which was modeled under the eddy viscosity assumption. The conventional Smagorinsky model (Smagorinsky, 1963) was used, and the eddy viscosity coefficient was modeled as

$$
\nu_{s g s}=\left(C_{s} f_{d} \Delta\right)^{2} \sqrt{2 \bar{S}_{i j} \bar{S}_{i j}}
$$


where $C_{s}$ is the model coefficient determined prior to the simulation, $\Delta$ is the length scale of the SGS turbulence expressed as the cube root of each numerical mesh, and $f_{d}$ represents the damping effect of SGS turbulence in the vicinity of the solid wall. A van Driest type damping function was used in this study; it is expressed as

$$
f_{d}=1-\exp \frac{-l^{+}}{25}
$$

where $l^{+}$is the distance from the solid wall in the wall coordinate normalized by the surface friction and kinetic viscosity.

For the model parameter, $C s=0.1$ was chosen in this study. The value was optimized on the surface pressure distribution of the vehicle in Fig. 1 from among three values: 0, 0.1, and 0.15. While the results were relatively sensitive to their values between $C s=0.1$ and 0.15 , the former showed better agreement with the experimental data, especially in the rear-end region.

\subsection{Discretization}

The governing equations were discretized in space by a vertex-centered unstructured finite volume method. Second-order central differences were mainly applied for the spatial derivative, blended with the first-order upwind scheme for the convective term in the Navier-Stokes equation to avoid excessive numerical oscillation appearing at coarse tetrahedral elements. It should be noted here that the dissipative behavior of upwind schemes is desirable to a certain extent for engineering applications of LES on unstructured meshes. As a compromise, the contribution of the upwind discretization to the convective fluxes was set as low as 5\%. The diffusive fluxes on the volume surface were treated on the basis of the deferred correction formula suggested by Muzaferija (1994) to avoid checkerboard-type oscillation. The MUSCL (monotone upwind scheme for conservation law) scheme by van Leer (1977) was also used for the convective term in regions away from the vehicle where the upwind dissipation does not affect the wake or near-wall turbulence of the target vehicle.

The time marching was based on the fractional step method by Kim \& Moin (1985), in which the third-order Adams-Moulton scheme or the implicit Euler scheme was used for the velocity prediction step. The coupling of the velocity and pressure fields to obtain the pressure and correct the velocity was based on the SMAC (simplified marker and cell) method by Amsden and Harlow (1970). The flow rate on the control-volume surface was estimated using the method proposed by Rhie and Chow (1983) to reduce checkerboard-type pressure oscillations. The pressure Poisson equation was solved by the incomplete Cholesky conjugate gradient (ICCG) method.

The computational code used in the present study was originally developed in the "Frontier Simulation Software for Industrial Science" project in Japan. It has been intensively optimized using high-performance computing techniques for LES for the vehicle aerodynamics (Tsubokura et al., 2007, 2008a, 2009), which allowed completion of the LES calculations of flow around a formula car with a complex geometry using 120 numerical meshes in about 120 hours.

\subsection{Numerical Setup}

The 1/20 wind tunnel model of a station-wagon-type vehicle is shown in Fig. 1. The definitions of drag, side and lift forces, as well as pitch, roll, and yaw moments with respect to each axis are also indicated. The overall 
length, width, and height of the model are $L=0.234 \mathrm{~m}, W=0.086 \mathrm{~m}$, and $H=0.074 \mathrm{~m}$. According to studies on the Ahmed reference model (e.g., Ahmed and Ramm, 1984), the vehicle's slant angle is a critical parameter for determining the topology of flow above the slant deck: the drag suddenly decreases above $30^{\circ}$, at which value the flow totally separates above the slant. The slant angle of the present model was about $45^{\circ}$ and was well into the supercritical region. The spoiler mounted at the roof's trailing edge also enhanced the flow separation. The surface geometry of the vehicle body was precisely reproduced from computer-aided design data for a real scale model, though for simplicity its underbody was made flat and the engine compartment was omitted. The solid surface was reproduced by triangular meshes with a spatial resolution of a few millimeters and covered by five layers of prism meshes to improve the accuracy of surface friction, as shown in Fig. 2. The finest triangular meshes smaller than $0.5 \mathrm{~mm}$ were allocated around the front pillars and the roof's trailing edge, where fine turbulence eddies were generated, while relatively coarse meshes of around $1.2 \mathrm{~mm}$ were used under the vehicle and over the front window, where the flow attached to the wall. The minimum thickness of the nearest prism layer on the wall was determined so as to keep its distance from the wall less than 10 in wall units $l^{+}$.

The rectangular computational domain, with its length, width, and height given as $11.9 \mathrm{~L}, 23.3 \mathrm{~W}$, and $13.5 \mathrm{H}$, is illustrated in Fig. 3. The blockage ratio with respect to the vehicle cross-section $A_{s}$ was less than $0.4 \%$, so the blockage correction was not applied to the obtained results. A uniform flow of $U_{0}=18.5 \mathrm{~m} / \mathrm{s}$ was the main inlet, and the vehicle was fixed on the floor at a distance $2.5 \mathrm{~L}$ downstream from the inlet plane. Another inlet condition was imposed on the domain's side wall to reproduce continuous or gusty crosswind fluctuations. The same inlet velocity condition was applied to the opposite side wall as a forced outlet condition to maintain a mass balance for the transverse direction. On the vehicle's surface and the tunnel's floor, the assumed profile for the main flow velocity (linear or log-law depending on the distance from the wall) was considered to determine the surface friction as a boundary condition on the wall. A free-slip velocity condition was applied to the ceiling, and the gradient-free condition was imposed on the outlet plane. For the outflow velocity boundary condition in LES, in which unsteady vortical structures pass through the outlet plane, a convective boundary condition (e.g., Lowery et al., 1987) should be used whenever possible to avoid numerical perturbation. On the other hand, one problem with the unstructured finite volume mesh is that its control volume surface is not necessarily perpendicular to the main flow direction. This becomes an issue around the outlet plane, and as a result, the validity of the convective boundary condition is canceled out by the surface non-orthogonal to the convective direction. Accordingly, we set the outlet plane far away from the vehicle to avoid the influence of the error generated by the gradient-free condition at the outlet. The MUSCL scheme was mainly used except for the rectangular sub-region illustrated by broken lines, in which the second-order central finite difference scheme was applied. To avoid excessive numerical oscillation induced by the central finite difference, we allocated relatively fine tetrahedral elements around the vehicle, as shown in Fig. 4. The total numbers of elements and nodes required for the simulation were about 20 million and 4 million, respectively.

In this study, the focus was a vehicle aimed straight ahead subjected to gusty or continuously fluctuating crosswinds, as schematically shown in Fig. 5 (upper). The flow field was reproduced in CFD by fixing the coordinates on the vehicle, and the crosswind region was convected downstream at the same speed as the assumed vehicle velocity. A typical case in which the vehicle is subjected to sudden crosswind is illustrated in Fig. 5 (lower), where a rectangular crosswind region is transported downstream. To achieve a convective crosswind, we imposed the crosswind's lateral velocity profile on the side of the computational domain and it 
was transported downstream at the same speed as the main inlet velocity (Tsubokura et al., 2008b). This convective crosswind method is similar to the wind-tunnel setup developed by Dominy \& Ryan (1999), in which a set of vertical axis shutters were mounted along the test section to realize the transient crosswind. The Reynolds number with respect to the main incoming flow $U_{0}$ and the vehicle length $L$ was $2.0 \times 10^{5}$.

All numerical simulations were conducted on an SR11000 (Hitachi) supercomputer at the Information Technology Center, University of Tokyo. Eight computational nodes (128 CPUs) were used to calculate each time-step in 3.3 real seconds. The simulations were time-integrated by the Euler implicit method for the first six thousand steps with a time increment of $\Delta \mathrm{t}=1 \times 10^{-5}$ to make the flow fully developed, and they were then switched by the third-order Adams-Moulton method with $\Delta \mathrm{t}=0.5 \times 10^{-5}$ for the next several ten thousand steps for precise prediction of the unsteady aerodynamics. The time increment was determined to give CFL numbers of less than 2 and 1 for the Euler implicit and Adams-Moulton methods, respectively.

\section{Results and Discussion}

\subsection{Validation}

The numerical method was validated in the static case in which the yaw angle $\beta$ was fixed to $0^{\circ}, 10^{\circ}, 20^{\circ}$, and $30^{\circ}$, and the aerodynamic forces and moments acquired numerically were compared with the wind tunnel data obtained by Tanaka et al. (2006). It should be noted that the experimental data were measured in a wind tunnel with its test section fully opened. The diameters of the round open jet and the round rear collector nozzles were $400 \mathrm{~mm}$ and $600 \mathrm{~mm}$, respectively. The distance between these two nozzles was $720 \mathrm{~mm}$, and the vehicle model was mounted on an acrylic plane with a length of $700 \mathrm{~mm}$ and width of $800 \mathrm{~mm}$. The vehicle centroid was located on the center-line $450 \mathrm{~mm}$ downstream from the plane's front edge.

The drag and side forces as well as the yaw moment obtained and their comparison with the experimental data are summarized in Fig. 6. The qualitative agreement with respect to the yaw angle change is satisfactory, whereas there is considerable disagreement in the side force at larger yaw angles. One possible explanation for the discrepancy is differences in the test section geometry between the present LES and the experiment. In the LES, the test section was fully closed with a blockage ratio less than $0.4 \%$, whereas in the wind tunnel measurement, it was open with an open jet diameter of only $400 \mathrm{~mm}$. Considering that the model length was $234 \mathrm{~mm}$, the interaction between the vehicle wake and the jet's free shear layer is not ignorable as the vehicle's yaw angle increases.

The surface pressure distributions on the vehicle's center-line in the cases of $\beta=0^{\circ}$ and $30^{\circ}$ are shown in Fig. 7. Generally, the LES results show good agreement with the experimental data. However, relatively large discrepancies were found at the roof and rear end under the body in the case of $\beta=30^{\circ}$ as well as at the middle of the underbody (between 0.36 and $0.46 \mathrm{~m}$ ) in the case of $\beta=0^{\circ}$, but the disagreement was limited and marginal.

\subsection{Continuous Yawing Change}

To investigate the effect of unsteady ambient wind on the vehicle aerodynamics, and especially its aerodynamic response to some specific wind frequencies, we overlapped the sinusoidal transverse velocity profiles on the main incoming flow. The crosswind profiles were imposed as an inlet/outlet boundary condition on both sides of the computational domain, as shown in Fig. 3. They are expressed as 
Because the sinusoidal profile travels at the same velocity as the inlet velocity, the frequency is given by $f=U_{0} / \lambda$.

According to the on-road measurement conducted by Wordley and Saunders (2008), the integral length-scale of turbulence around a vehicle in on-road driving is strongly dependent on the ambient environment around the road. The maximum length was observed in smooth terrain and reached around twenty meters (corresponding to about five times the vehicle length), with a turbulence intensity as low as $2 \%$ to $6 \%$. The minimum length was identified in a freeway traffic condition and was less than five meters (about the same as the vehicle length), while its turbulence intensity had a wide range up to $16 \%$. In the present study, two wavelengths $\lambda=1.3 \mathrm{~L}$ and $2.6 \mathrm{~L}$ were mainly considered. With incoming velocity of $18.5 \mathrm{~m} / \mathrm{s}$ and vehicle length $L=0.234 \mathrm{~m}$, the crosswind frequency acting on the model vehicle was $60 \mathrm{~Hz}(\lambda=0.31 \mathrm{~m})$ and $30 \mathrm{~Hz}$ ( $\lambda=0.63 \mathrm{~m}$ ). The corresponding Strouhal numbers $S_{t}$ with respect to $L$ and $U_{0}$ were 0.76 and 0.38 , respectively. For reference, a relatively longer length-scale of $\lambda=7.9 \mathrm{~L}$ was also used. The fluctuation amplitudes were determined so as to vary the vehicle's relative yaw angle $\beta$ with respect to the incoming flow between $-10^{\circ}$ and $+10^{\circ}$ or $-15^{\circ}$ and $+15^{\circ}$. The transient yaw angle was defined by the reference crosswind velocity at the point about $6.5 \mathrm{H}$ above the origin of the moment axes. The sinusoidal transversal velocity profile imposed on the incoming flow and its wavelength and amplitude are summarized in Fig. 8. As a result of the sinusoidal crosswind, sinusoidal yawing was imposed on the vehicle.

The time series of the aerodynamic forces and moments in the cases of $(\beta, \lambda)=\left( \pm 10^{\circ}, 2.6 L\right),\left( \pm 10^{\circ}, 1.3 L\right)$, and $\left( \pm 15^{\circ}, 2.6 L\right)$ are plotted in Figs. 9, 10, and 11, respectively. The reference crosswind profile measured above the vehicle is also indicated. The sinusoidal aerodynamic responses of the side force as well as the yaw and roll moments are remarkable, while their phases are slightly shifted with respect to the crosswind velocity. The drag, lift, and roll are relatively perturbed and their sinusoidal responses are somewhat ambiguous, while their frequency is twice that of the crosswind velocity.

Snapshots of the lateral velocity distributions around the vehicle and the surface pressure contours are visualized in Fig. 12. We can see that the vehicle went straight ahead through the sinusoidal crosswind at two different wavelengths. While the crosswind velocity profiles slightly decayed downstream of the vehicle, owing to the coarser numerical grids allocated, it is not critical in estimating the unsteady aerodynamic forces acting on the vehicle. It is remarkable that in the case of $\lambda=1.3 L$, because the wavelength is comparable to the vehicle length, a crosswind velocity with the opposite direction acted on the vehicle at the same time and multiple flow structures appeared around the vehicle.

The trajectories of the phase-averaged drag, side forces, and yaw moment with respect to the relative yaw angle $\beta$ are illustrated in Fig. 13, where the arrow indicates the direction of trajectory motion. The static aerodynamic forces measured by fixing the yaw angle at $0^{\circ}, 10^{\circ}$, and $20^{\circ}$ at the corresponding relative incoming velocity $V_{0}$ are also plotted for reference. At this relatively smaller yawing change, all three indicated aerodynamic components in the static case increased almost linearly with respect to the yaw angle, which is given by the dash-dotted line in the figure. It should be noted that the gradient lines are generally utilized for an analysis based on the conventional quasi-steady assumption.

In all cases, the drag trajectory had a butterfly pattern, which indicates that the drag response frequency was twice that of the input sinusoidal yawing. As the wavelength deceased, its dependence on the yaw angle 
represented by the gradient of the trajectory became smaller. In the typical case of $(\beta, \lambda)=\left( \pm 15^{\circ}, 2.6 L\right)$, the value varied between 0.32 and $0.41 \mathrm{~N}$ and its displacement was $0.09 \mathrm{~N}$. On the other hand, with the the quasi-steady assumption, the value varied between 0.34 at $\beta=0^{\circ}$ and $0.48 \mathrm{~N}$ at $\beta=15^{\circ}$, and its displacement was estimated to be $0.14 \mathrm{~N}$. Thus, the conventional quasi-steady analysis overestimated the value by more than $50 \%$. On the other hand, in the case of a smaller wavelength, $(\beta, \lambda)=\left( \pm 10^{\circ}, 1.3 L\right)$, the significant dependence on continuous yawing disappeared. The mean drag under continuous yawing slightly increased at the wavelength of $\lambda=2.6 L$, as shown in Table 1 . As the wavelength became smaller and more comparable to the vehicle length, no significant increases in the averaged drag were identified.

The trajectory of the side force and yaw moment was ellipsoidal and rotationally symmetric, indicating that the aerodynamic response was sinusoidal with the same frequency as the sinusoidal yawing. The width of the ellipsoid reflects the phase shift with respect to the frequency of the transient yaw angle. In both cases, the elliptical trajectories at the same wavelength of $\lambda=2.6 \mathrm{~L}$ were similar between $\beta= \pm 10^{\circ}$ and $\pm 15^{\circ}$, indicating that they were synchronized with each other and that the only difference was the magnitude, which strictly followed the relative velocity $V_{0}$.

In the side-force trajectory, as the wavelength $\lambda$ increased to $7.9 \mathrm{~L}$, it became almost linear and was close to the quasi-steady line; hence, no significant unsteady effect was observed. On the other hand, as the wavelength $\lambda$ became smaller and closer to the vehicle length; the trajectory became more circular, which suggests that the phase shift against the input yawing became larger. It is interesting to note that the gradient of the side force $d F_{y} / d \beta$ in the case of $\lambda=2.6 L$, represented by the major axis of the ellipse and expressed by the dash-dotted line in the figure, was less steep than that of the static case (quasi-steady). As the wavelength was reduced to half $(\lambda=1.3 L), d F_{y} / d \beta$ slightly decreased. Accordingly, the discrepancy in the maximum side force between the dynamic and static cases became wider as the yaw angle increased or the wavelength decreased. Generally speaking, the discrepancy in the side force from the quasi-steady assumption became critical when the wavelength was up to about three times the vehicle length.

On the other hand, in the yaw moment, the phase shift represented by the elliptical trajectory appeared even at $\lambda=7.9 \mathrm{~L}$ and was enhanced as the wavelength became smaller, while the gradient of the yaw moment $d M_{z} / d \beta$ was identical between the static and dynamic cases at $\lambda=2.6 L$ and $7.9 L$. In addition, unlike the side force, the minimum yaw moment at $\beta=10^{\circ}$ in the case of $\lambda=2.6 \mathrm{~L}, 7.9 \mathrm{~L}$ and in the static case were also almost identical. In the same manner, the minimum yaw moment at $\beta= \pm 15^{\circ}$ in the case of $(\beta, \lambda)=\left( \pm 15^{\circ}, 2.6 L\right)$ can be estimated from the static results. The difference between the cases with $\lambda=2.6 L$ and $1.3 L$ is also remarkable. The major axis of the elliptical trajectory representing $d M_{z} / d \beta$ is significantly smaller at $\lambda=1.3 L$ and close to horizontal, suggesting that the yaw moment is less dependent on the yaw angle when the crosswind wavelength is comparable to the vehicle length. The mean lift force and mean pitch moment were more or less affected by the sinusoidal yawing, as shown in Table 1. It is notable that the lift was strongly affected by the imposed magnitude $A$ and that the downforce was decreased by almost $35 \%$ by the continuous yawing change at $\beta= \pm 15^{\circ}$. On the other hand, the pitch depended on the imposed frequency, and its magnitude decreased by $20 \%$ when the wavelength was increased from $\lambda=1.3 L$ to $\lambda=2.6 L$.

\subsection{Gusty Crosswind}

To understand the influence of an unexpected gust on the vehicle's aerodynamic performance, we imposed a stepwise transversal velocity profile on the main incoming flow. The crosswind profile was determined in 
order to create the situation where the straight-ahead-pointing vehicle rushed into the crosswind region and the vehicle's relative yaw angle with respect to the incoming flow rapidly changed from $0^{\circ}$ to $30^{\circ}$. The velocity of the main incoming flow was fixed at $U_{0}=18.5 \mathrm{~m} / \mathrm{s}$, and the transversal velocity was changed from 0 to 10.7 $\mathrm{m} / \mathrm{s}$. The imposed crosswind was not exactly stepwise but was approximated by 6th-order polynomials to avoid numerical oscillation.

The time history of the acquired unsteady aerodynamic forces is illustrated in Fig. 14. The vehicle's nose and tail reached the crosswind interface at $\mathrm{T}=0.283 \mathrm{~s}$ and $0.296 \mathrm{~s}$, respectively, and the shaded area indicates that the vehicle was subjected to the crosswind during this time period. Because the incoming flow velocity increased from 18.5 to $21.4 \mathrm{~m} / \mathrm{s}$ during the process, all six aerodynamic forces finally increased to some degree when a sufficiently long time had passed after the rushing-in process. On the other hand, their transient growth was independent of the fixed yaw-angle case indicated in Fig. 6. Whereas the side force increased monotonically with time, the drag and lift first undershot and overshot in the initial stage of the rushing-in process and then monotonically increased to reach the steady-state. It is notable that compared with the drag and side forces, a relatively longer time period was required for the lift to become steady.

The nonlinear aerodynamic response with respect to the time path can be seen more clearly in the moments: all three components showed drastic overshoots or undershoots. Among them, the undershoot of the yaw moment has been widely acknowledged (e.g., Beauvais, 1967). It has also been reported that this undershoot is caused by separation at the vehicle's corner and is thus geometry-dependent. The sudden increases in the pitch moment and the lift force are also remarkable because they degrade the vehicle's running stability. In addition, similar to the lift force, these two components also showed a longer relaxation time before reaching the steady state. It seems that distances two to three times longer than the vehicle length were required for the aerodynamic response to settle down after the vehicle's nose reached the crosswind interface, so the transient response lasted until around $\mathrm{t}=0.33 \mathrm{~s}$.

To investigate the nonlinear response and the time delay, we visualized the flow structures and surface pressure. Snapshots of vortical structures around the vehicle at three consecutive times before, during, and after the rushing-in process are shown in Fig. 15. Typical flow structures, such as the front pillar vortices, were identified just before the rush-in and were symmetric with respect to the vehicle center-plane. Strong flow separation at the leeward front pillar was identified just after the rush-in, as shown in Fig. 15(b), while the wake was seemingly unaffected by the crosswind. The development of side separation continued until it ran down to the wake and they interacted with each other, as shown in Fig. 15(c).

The time variation in the surface pressure snapshot is visualized in Fig. 16. The separation of the flow at the roof's windward corner represented by the low pressure was remarkable at $\mathrm{T}=0.2925 \mathrm{~s}$ and propagated downstream as time passed. At $\mathrm{T}=0.330 \mathrm{~s}$, separation at the roof's entire windward corner was observed. The propagation of the separation also enhanced the separation above the roof, and the low-pressure region spread over the roof. However, the process is rather sequential and does not explain the nonlinear increase in the lift, pitch, and roll seen in Fig. 14. On the other hand, drastic unsteady phenomena were observed under the body. At $\mathrm{T}=0.2975 \mathrm{~s}$, just after the entire body was subjected to the crosswind, a flow separation represented by the low pressure was found behind the windward front and rear wheels, although it was mitigated as time passed, as shown at $\mathrm{T}=0.330 \mathrm{~s}$. Undershooting of the pitch and roll as well as overshooting of the lift were observed at around $\mathrm{T}=0.2975 \mathrm{~s}$; thus, it is reasonable to say that these were caused by the intensive flow separation around the windward side. 


\section{Conclusions}

An LES method for the unsteady aerodynamics of road vehicles was developed on the basis of a fully unstructured finite volume method, and the unsteady aerodynamic response of a road vehicle subjected to two types of transient crosswinds was investigated.

In the continuous sinusoidal yawing case, all six components of the aerodynamic forces and moments showed more or less sinusoidal responses, with phase shifts depending on the imposed wavelength. The unsteady effect represented by the difference from the quasi-steady assumption was remarkable when the wavelength was comparable to the vehicle length. Considering that the typical integral length-scale of ambient wind around a road vehicle is comparable to the vehicle length (Wordley and Saunders, 2008), the limitation of the quasi-steady assumption based on conventional wind tunnel measurements was determined to take into account the ambient turbulence in vehicle aerodynamics.

In the gusty crosswind case, overshooting or undershooting of the transient aerodynamic forces and moments while the vehicle was rushing into the crosswind region was observed. In addition to the well-known undershooting of the yaw moment reported by Beauvais (1967), the drag, lift, pitch, and roll also showed nonlinear responses. The relaxation time for each aerodynamic force or moment to reach a statistically steady state was found to depend on each component, and relatively longer times were required for the lift force as well as for the roll and pitch moments. The reason for the longer relaxation time was explained by the transient reaction of underbody flow, which is represented by the drastic separation and mitigation observed around the windward wheels. This result indicates the importance of the underbody shape for crosswind safety.

Finally, it should be noted that although only one specific vehicle shape was investigated in this study, the results obtained here can be applied to any standard-sized car, especially in the context of describing the importance of the ambient turbulence comparable to the vehicle length and the underbody flow for crosswind safety.

\section{Acknowledgements}

This work was mainly supported by the Industrial Technology Research Grant Program in 2007 from the New Energy and Industrial Technology Development Organization (NEDO) of Japan. It was partly supported by a Grant-in-Aid for Scientific Research from JSPS (No. 20560143) and the NRL of NRF of Korea (R0A-2008-000-20069-0). This study was conducted in a collaborative research project with Fuji Heavy Industries Ltd., and the shape data and experimental data received are greatly acknowledged. 
References

Ahmed, S. R., Ramm, G., and Galtin, G., 1984, "Some salient features of the time-averaged ground vehicle wake," SAE Technical paper series, 840300

Amsden, A. A. and Harlow, F. H., 1970, "A simplified MAC technique for incompressible fluid flow calculations," Journal of Computational Physics, vol. 6, pp. 322-325

Beauvais, F. N., 1967, "Transient nature of wind gust effect on an automobile," SAE Technical Paper 670608

Cooper, K. R. and Campbell, W. F., 1983, "An examination of the effects of wind turbulence on the aerodynamic drag of vehicle," Journal of Wind Engineering and Industrial Aerodynamics, vol. 9, pp. 167-180.

Cooper, K. R. and Watkins, S., 2007, “The unsteady wind environment of road vehicles, Part one: A review of the on-road turbulent wind environment," SAE Technical Paper Series 2007-01-1236

Cogotti, 2003, "Generation of a controlled level of turbulence in the Pininfarina wind tunnel for the measurement of unsteady aerodynamics and aeroacoustics," SAE Technical Paper Series 2003-01-0430

Cogotti, 2004, "Update on the Pininfarina "turbulence generation system" and its effects on the car aerodynamics and aeroacoustics," SAE Technical Paper Series 2004-01-0807

Dominy, R. G. and Ryan, A., 1999, "An improved wind tunnel configuration for the investigation of aerodynamic cross wind gust response," SAE Technical Paper Series 1999-01-0808

Fares, E., 2006, "Unsteady flow simulation of the Ahmed reference body using a lattice Boltzmann approach,” Computers \& Fluids, vol. 35, pp. 940-950

Guilmineau, E., 2008 "Computational study of flow around a simplified car body," Journal of Wind Engineering and Industrial Aerodynamics, vol. 96, pp. 1207-1217

Guilmineau, E. and Chometon, F., 2008, "Numerical and experimental analysis of unsteady separated flow behind an oscillating car model," SAE Technical Paper Series 2008-01-0738

Hemida, H. and Krajnović, S., 2009, "Transient simulation of the aerodynamic response of a double-deck bus in gusty winds," Journal of Fluids Engineering, Transactions of ASME, vol. 131, pp. 031101-1 031101-10

Kim, J. and Moin, P., 1985, “Application of a fractional step method to incompressible Navier-Stokes equations," Journal of Computational Physics, vol. 59, pp. 308-323

Krajnović, S. and Davidson, L., 2005, "Flow around a simplified car, Part 1: Large Eddy Simulation," Journal of Fluid Engineering, vol. 127, pp. 907-918

Krajnović, S. and Davidson, L., 2005, "Flow around a simplified car, Part 2: Understanding the flow," Journal of Fluid Engineering, vol. 127, pp. 919-928

van Leer, B., 1977, "Toward the ultimate conservative difference scheme 4, a new approach to numerical convection,” Journal of Computational Physics, vol. 23, pp. 276-99

Lowery, P. S., Reynolds, W. C., and Mansour, N. N., 1987, Passive scalar entrainment and mixing in a forced, spatially developing mixing layer, AIAA-87-0132

Minguez, M., Pasquetti, R., and Serre, E., 2008, "High-order large-eddy simulation of flow over the “Ahmed body” car model," Physics of Fluids, vol. 20, 095101

Muzaferija, S., 1994, "Adaptive finite volume method for flow predictions using unstructured meshes and multigrid approach," Ph.D. thesis, University of London

Okumura, K. and Kuriyama, T., 1997, "Transient aerodynamic simulation in crosswind and passing an automobile," SAE Technical Paper Series 970404 
Rhie, C. M. and Chow W. L., 1983, “A numerical study of the turbulent flow past an isolated airfoil with trailing edge separation," AIAA Journal, vol. 21, pp. 1525-32

Smagorinsky, J., 1963, "General circulation experiments with the primitive equations, I. The Basic Experiment," Monthly Weather Rev., vol. 91, no. 3, pp. 99-164

Tanaka, F., Kawaguchi, K., Sunohara, K., Hasegawa, T., and Takada, K., 2006, "Flow around vehicle model (Study of numerical accuracy of yawing moment)," Proc. of the 20th Symp. on Computational Fluid Dynamics, A6-2, in Japanese

Tsubokura, M., Kitoh, K., Oshima, N., Nakashima, T., Zhang, H., Onishi, K., and Kobayashi, T., 2007, "Large Eddy Simulation of unsteady flow around a formula car on Earth Simulator," SAE 2007 Trans. J. of Passenger Cars -Mechanical Systems, 2007-01-0106

Tsubokura, M., Kobayashi, T., Nakashima, T., Nouzawa, T., Nakamura, T., Zhang, H., Onishi, K., and Oshima, N., 2008a, "Computational visualization of unsteady flow around vehicles using High Performance Computing," Computers \& Fluids, vol. 38, pp. 981-990

Tsubokura, M., Nakashima, T., Ikenaga, T., Onishi, K., Kitoh, K., Oshima, N., and Kobayashi, T., 2008b, "HPC-LES for the prediction of unsteady aerodynamic forces on a vehicle in a gusty cross-flow condition," SAE Technical Paper 2008-01-300

Tsubokura, M., Nakashima, T., Kitoh, K., Sasaki, Y., Oshima, N., and Kobayashi, T., 2009, "Development of an unsteady aerodynamic simulator using large-eddy simulation based on high-performance computing technique," SAE Technical paper series 2009-01-0007

Wordley, S. and Saunders, J., 2008, “On-road Turbulence,” SAE Technical Paper, no. 2008-01-0475 
Figure captions

Table 1 Averaged drag, lift, and pitch moments in the continuous yawing case.

Figure 1 Orthogonal views of the station-wagon vehicle (1/20th scale model).

Figure 2 Surface grid allocations on the vehicle: (a) surface reproduction by triangular elements and (b) five prism layers near the solid wall.

Figure 3 Analysis region.

Figure 4 Far-field grid allocations around the vehicle: (a) vertical section on the center-plane and (b) horizontal section on the floor.

Figure 5 Three subsequent moments for a vehicle facing straight ahead and rushing into a crosswind region (shaded area): A, running straight ahead; B, just reaching the crosswind interface; C, immersed in the crosswind region. Upper, the static system fixed on the ground; lower, relative coordinates fixed on the vehicle.

Figure 6 Aerodynamic forces and moment versus yawing angle in the static condition.

Figure 7 Surface pressure distribution along the center-line in the static condition: (a) $\beta=0^{\circ}$ and (b) $\beta=30^{\circ}$.

Figure 8 Overview of the sinusoidal crosswind imposed.

Figure 9 Time history of unsteady aerodynamic forces and moments in a continuous yawing angle change, $\pm 10^{\circ} / \lambda=2.6 L$ : (a) forces and (b) moments.

Figure 10 Time history of unsteady aerodynamic forces and moments in a continuous yawing angle change, $\pm 10^{\circ} / \lambda=1.3 L$ : (a) forces and (b) moments.

Figure 11 Time history of unsteady aerodynamic forces and moments in a continuous yawing angle change, $\pm 15^{\circ} / \lambda=2.6 L$ : (a) forces and (b) moments.

Figure 12 Crosswind distribution around the vehicle and the surface pressure distribution: left, $\lambda=2.6 L$ and $\beta= \pm 10^{\circ}$; right, $\lambda=1.3 L$ and $\beta= \pm 10^{\circ}$.

Figure 13 Trajectory of the aerodynamic response: left, drag force; center, side force; right, yaw moment.

Figure 14 Time history of unsteady aerodynamic forces and moments in a sudden crosswind: (a) forces and (b) moments.

Figure 15 Snapshots of the iso-surface of vorticity magnitude before, during, and after the rushing-in process:

(a) $\mathrm{T}=0.25 \mathrm{~s}$; (b) $\mathrm{T}=0.29 \mathrm{~s}$; and (c) $\mathrm{T}=0.32 \mathrm{~s}$.

Figure 16 Snapshots of the pressure contours on the vehicle surface at $\mathrm{T}=0.275,0.2925,0.2975$, and $0.330 \mathrm{~s}$. 
Table 1 Average drag, lift, and pitch moments in the continuous yawing case.

\begin{tabular}{|c|c|c|c|c|}
\hline & Steady flow & $\beta= \pm 10^{\circ} / \lambda=2.6 L$ & $\beta= \pm 10^{\circ} / \lambda=1.3 L$ & $\beta= \pm 15^{\circ} / \lambda=2.6 L$ \\
\hline Drag [N] & 0.343 & 0.348 & 0.348 & 0.364 \\
\hline Lift [N] & -0.195 & -0.189 & -0.182 & -0.127 \\
\hline Pitch [Nm] $\times 10^{-3}$ & -7.56 & -6.05 & -6.89 & -6.06 \\
\hline
\end{tabular}




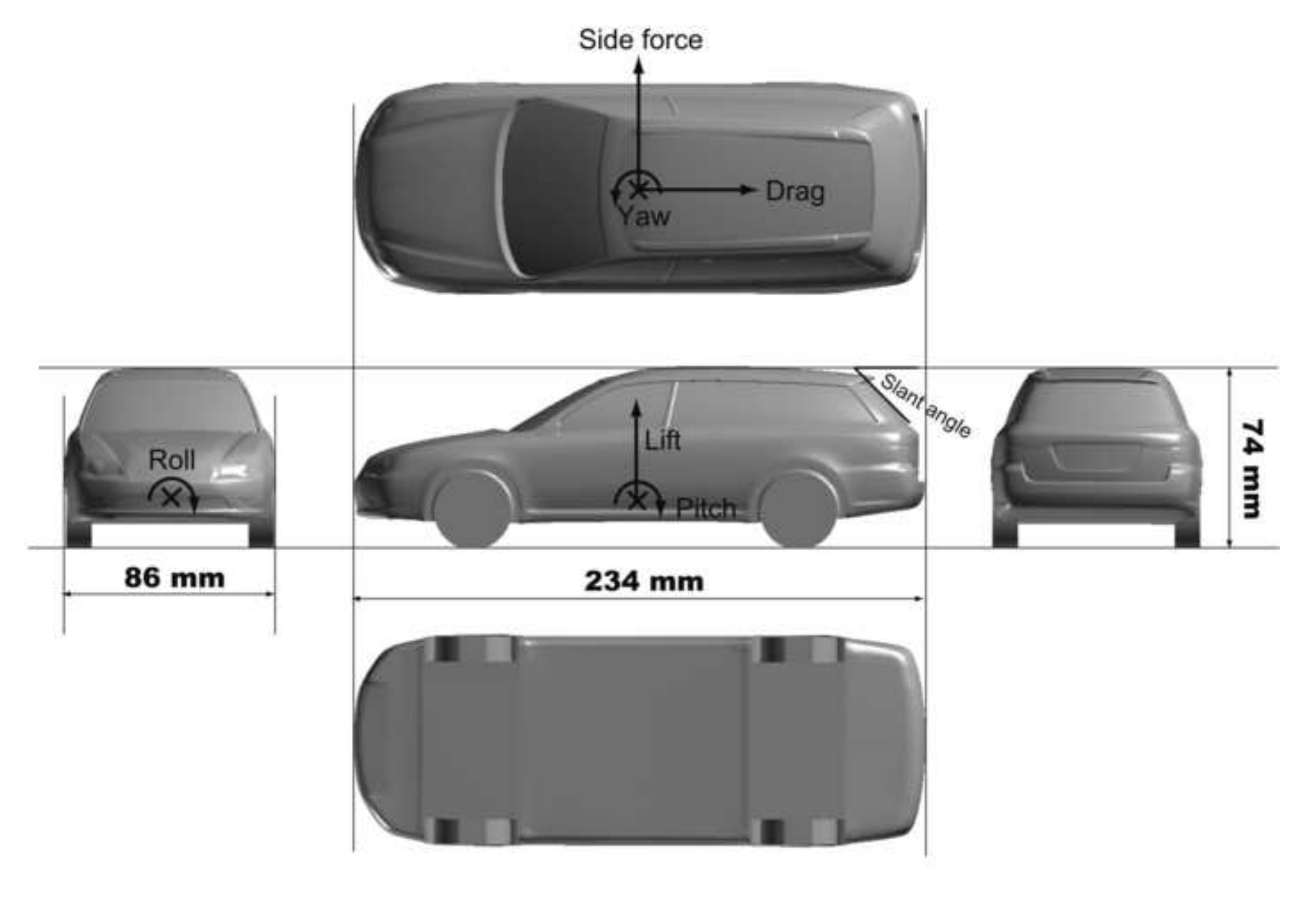$$
\text { . }
$$
.

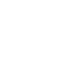

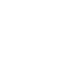

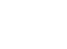

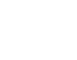

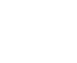
. .

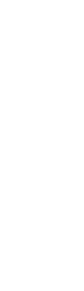

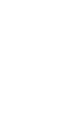


Click here to download high resolution image

(a)

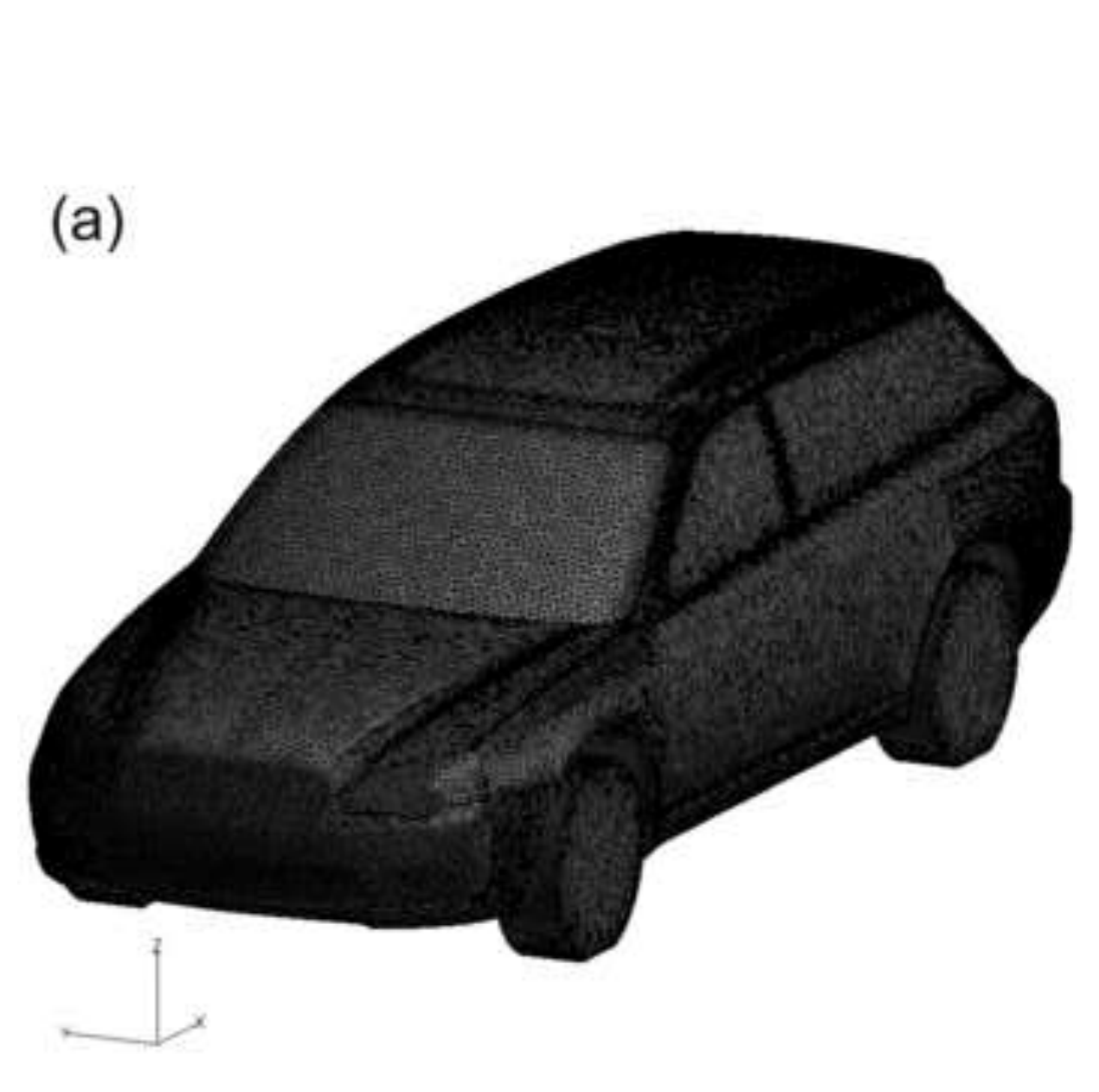

(b)

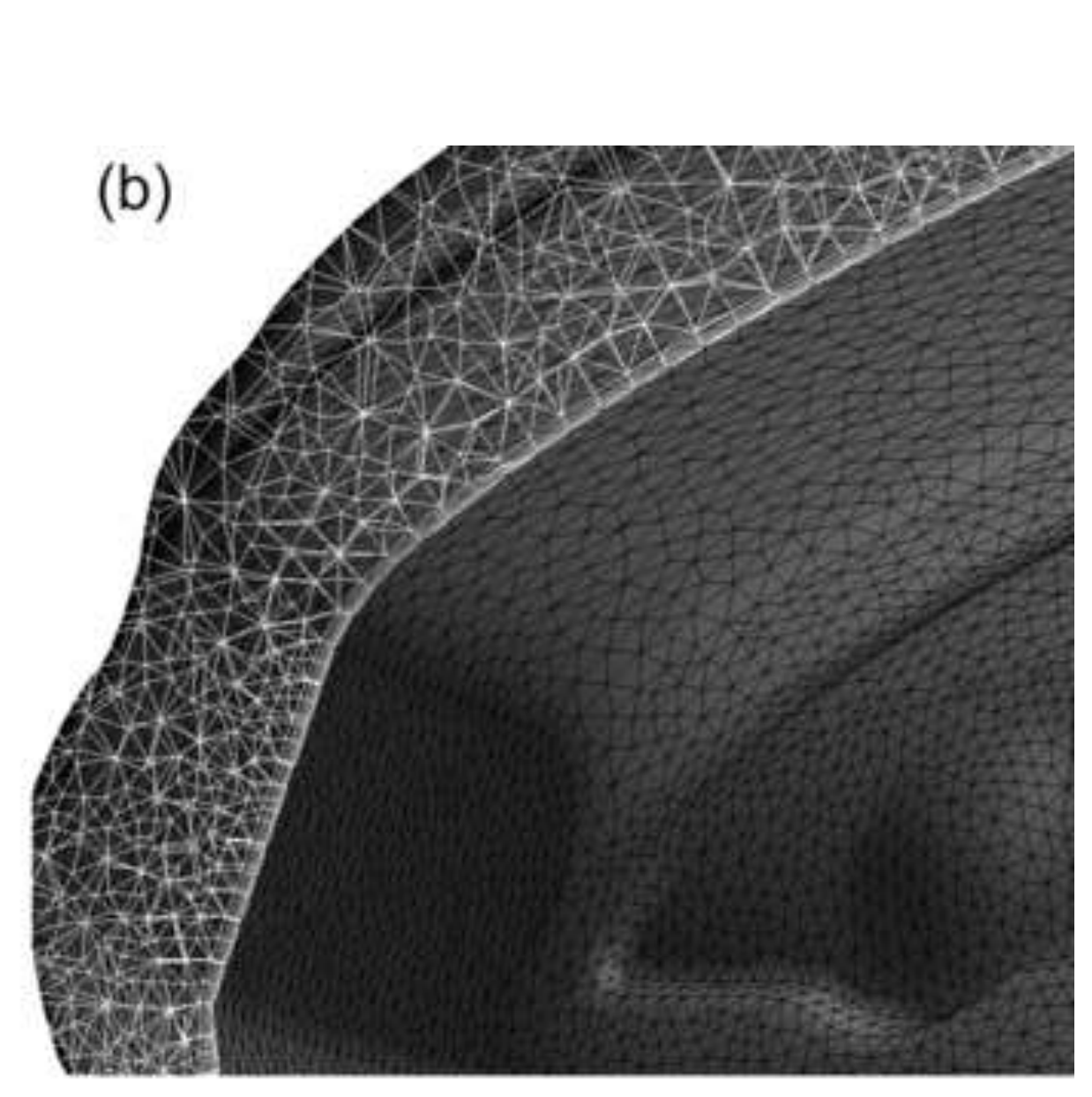




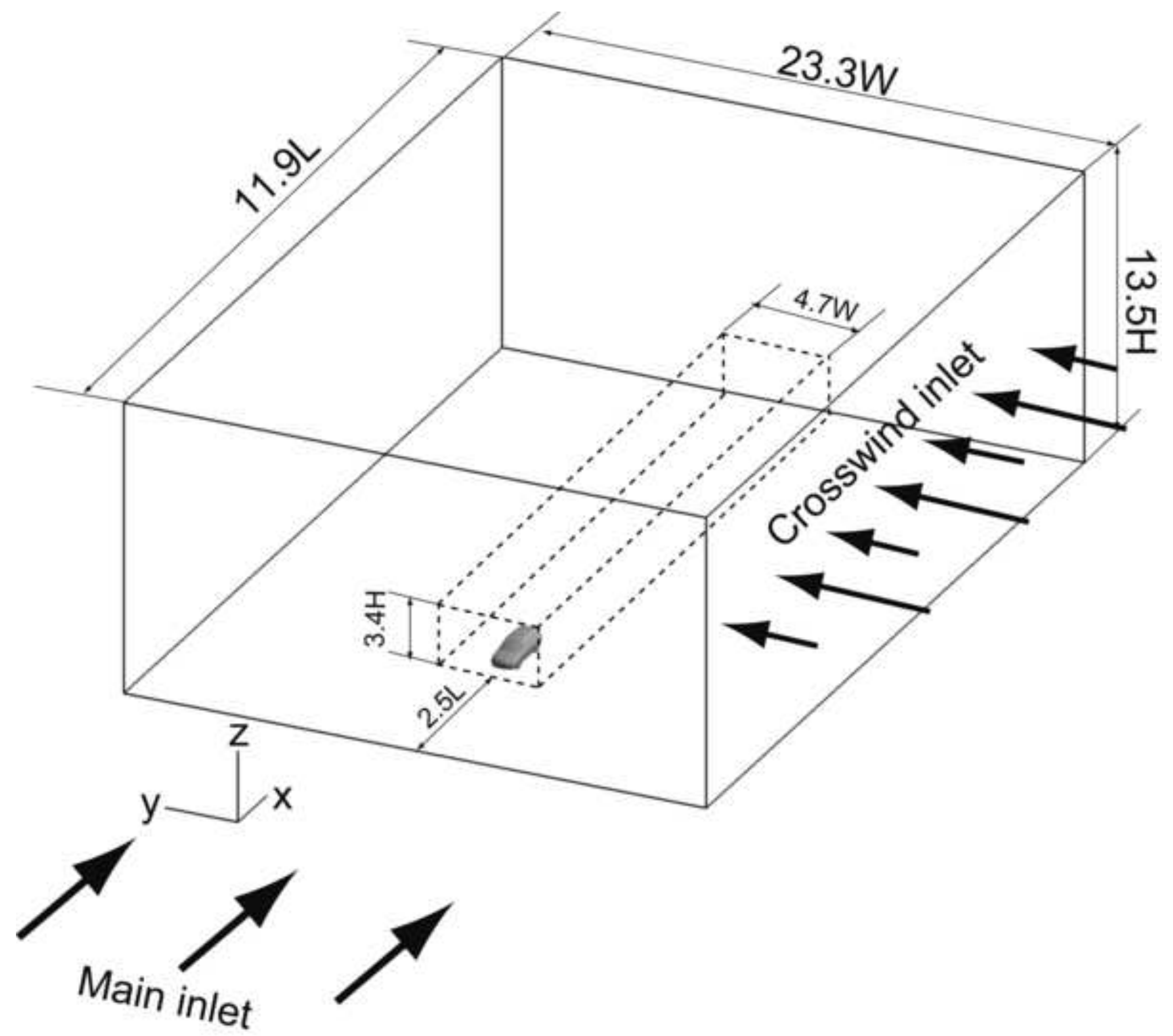


(a)

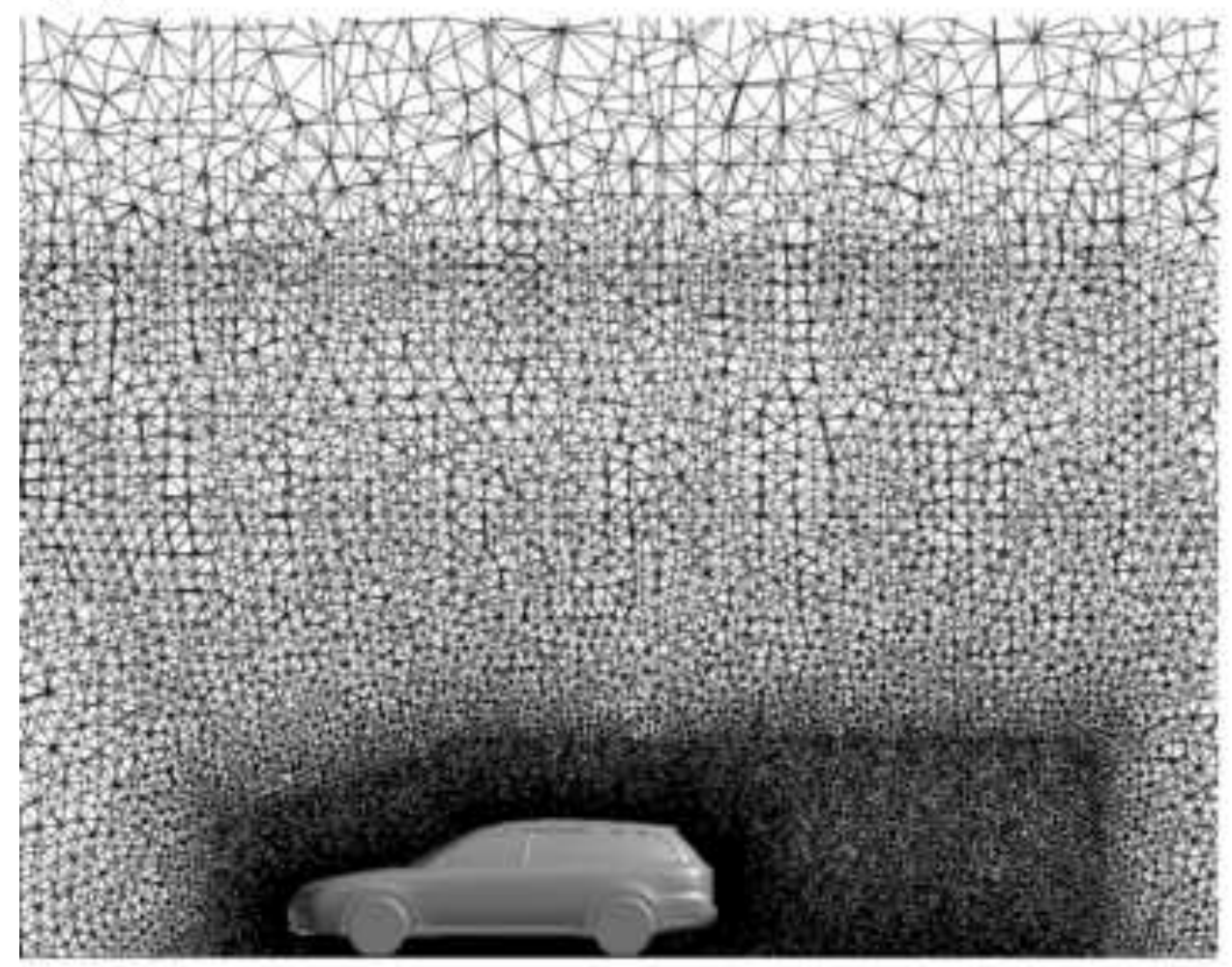

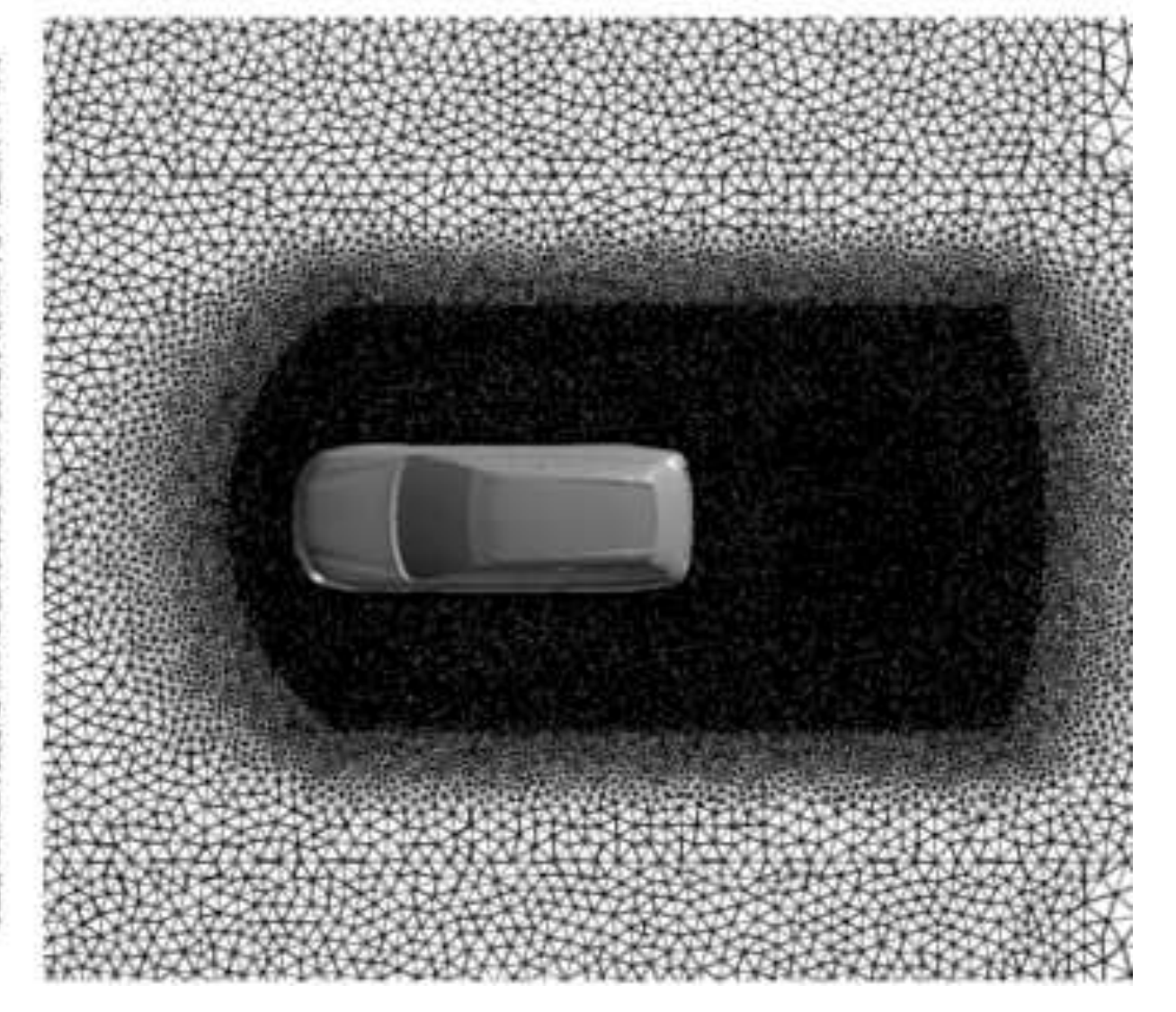

) \\ (a)}


Coordinates fixed on the ground
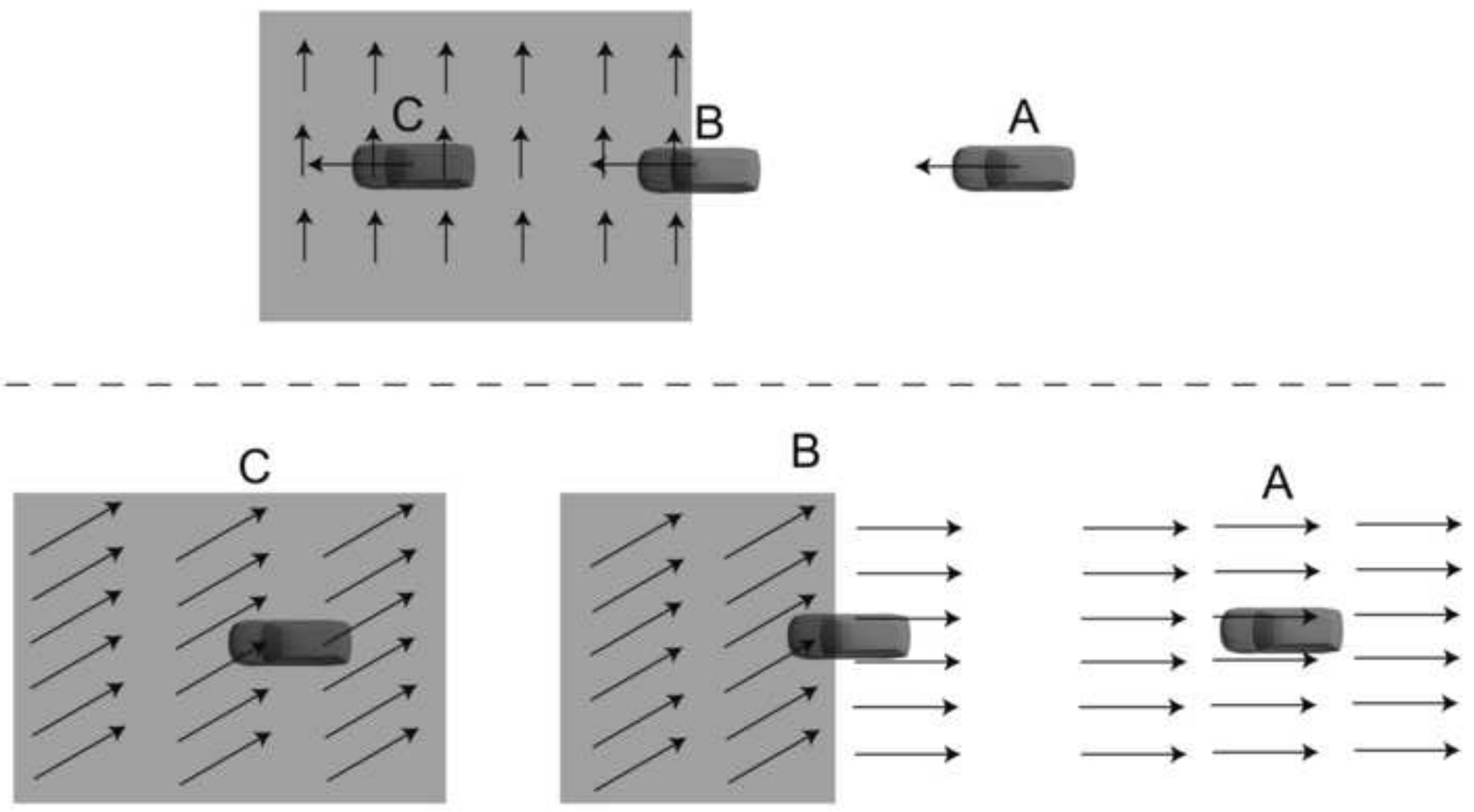

Coordinates fixed on the vehicle 
Click here to download high resolution image
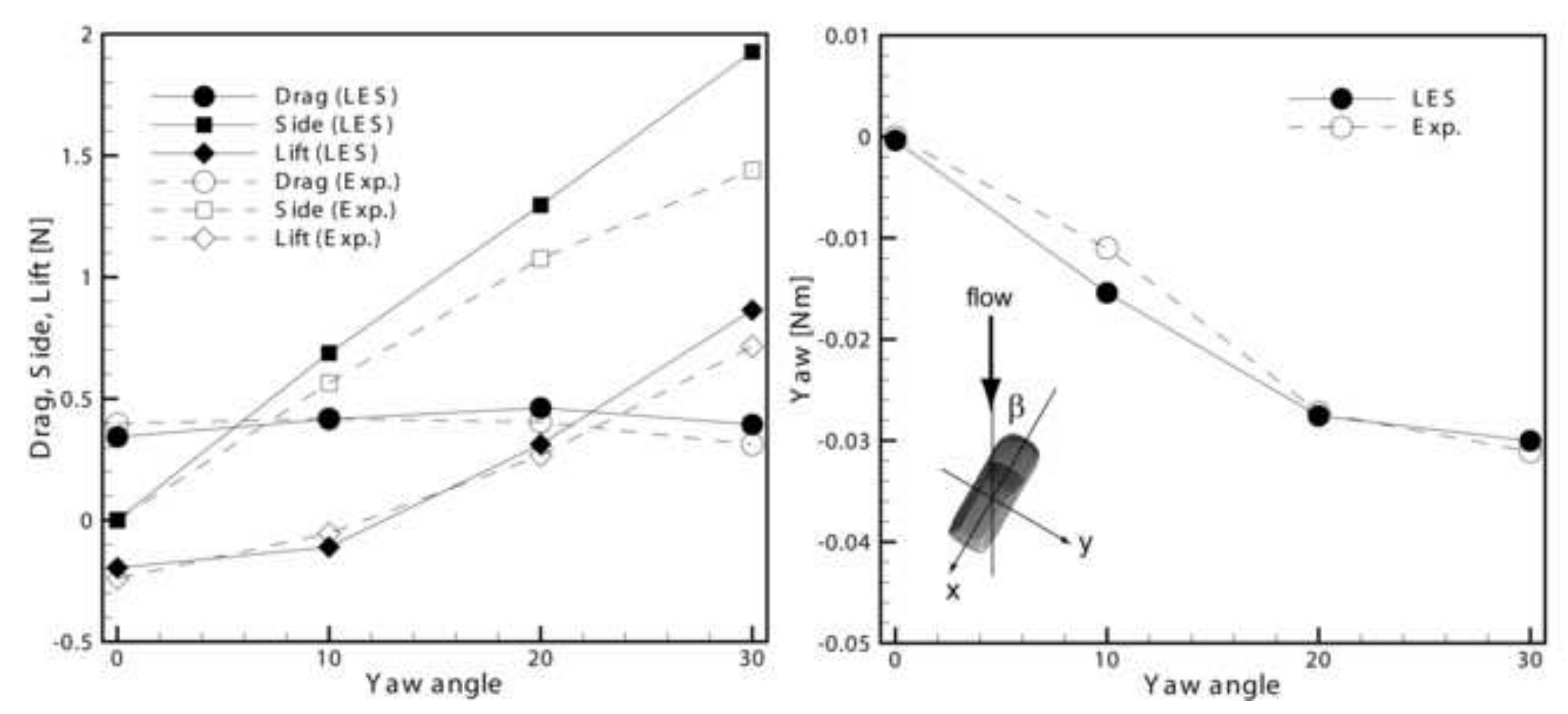

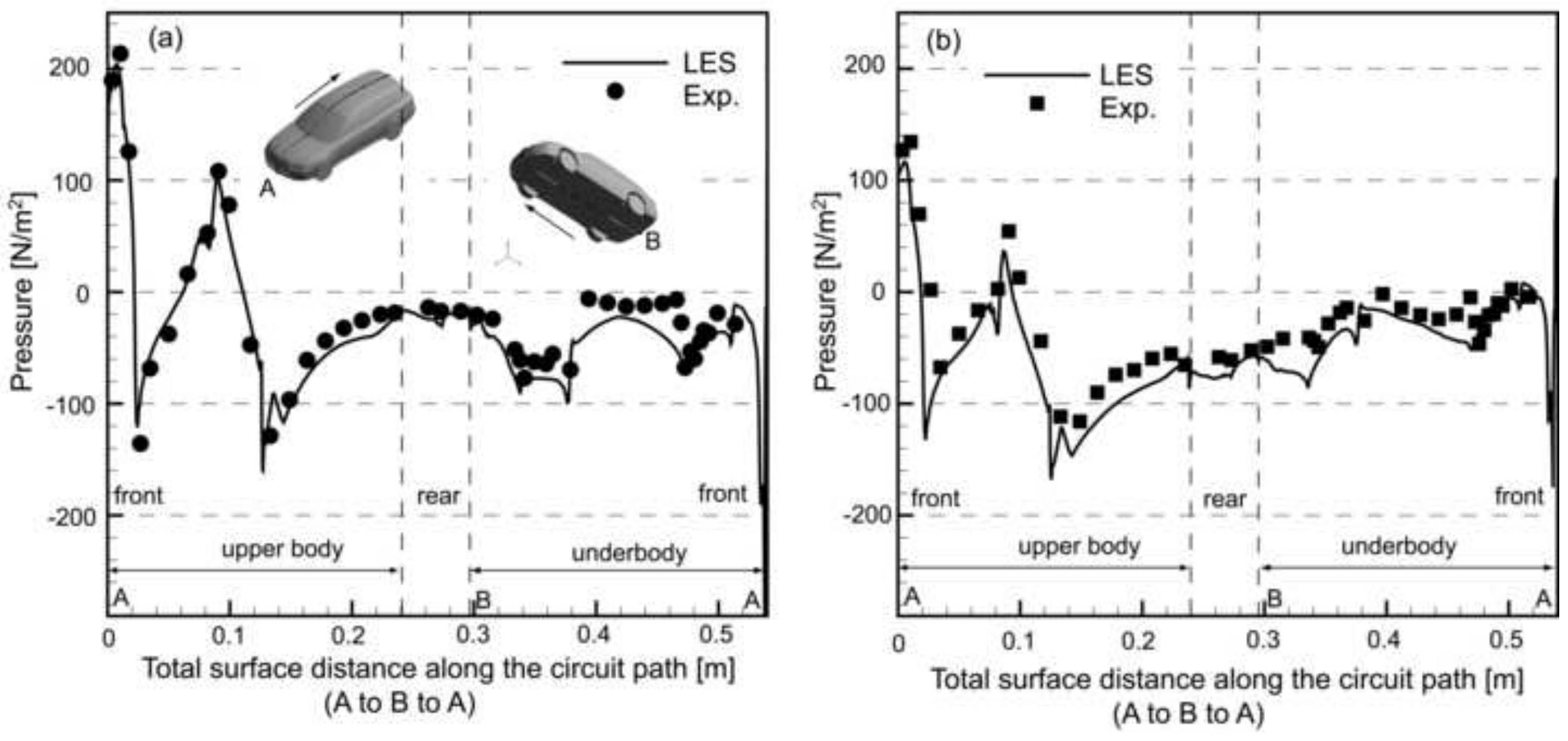


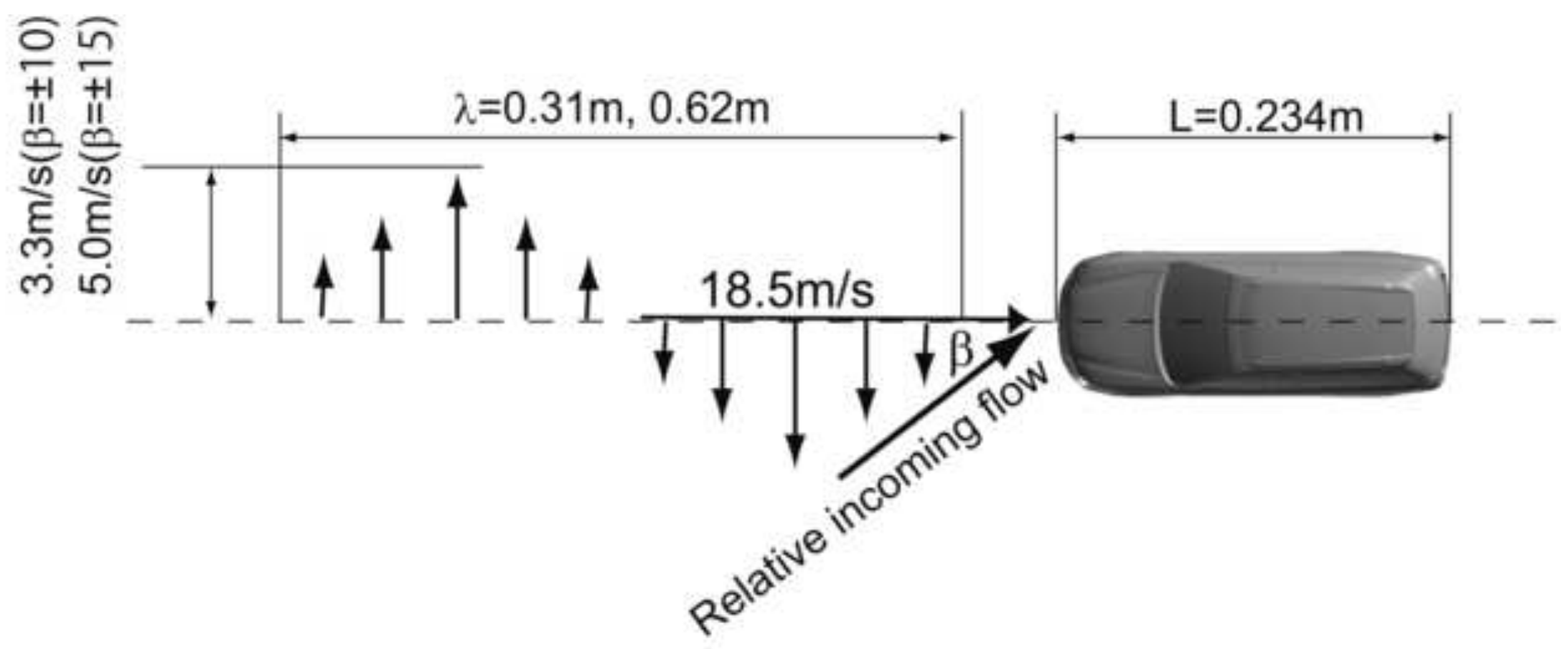



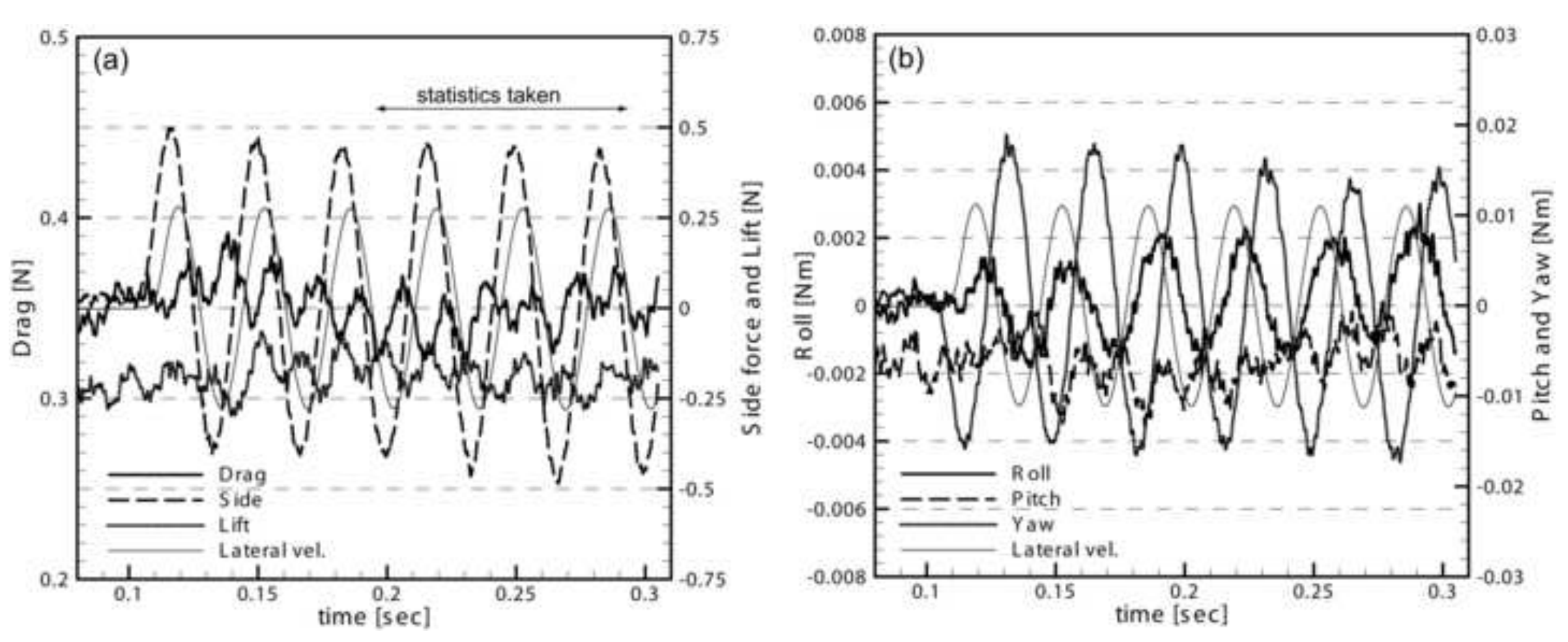

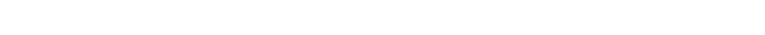

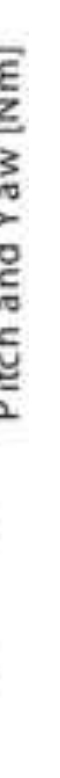



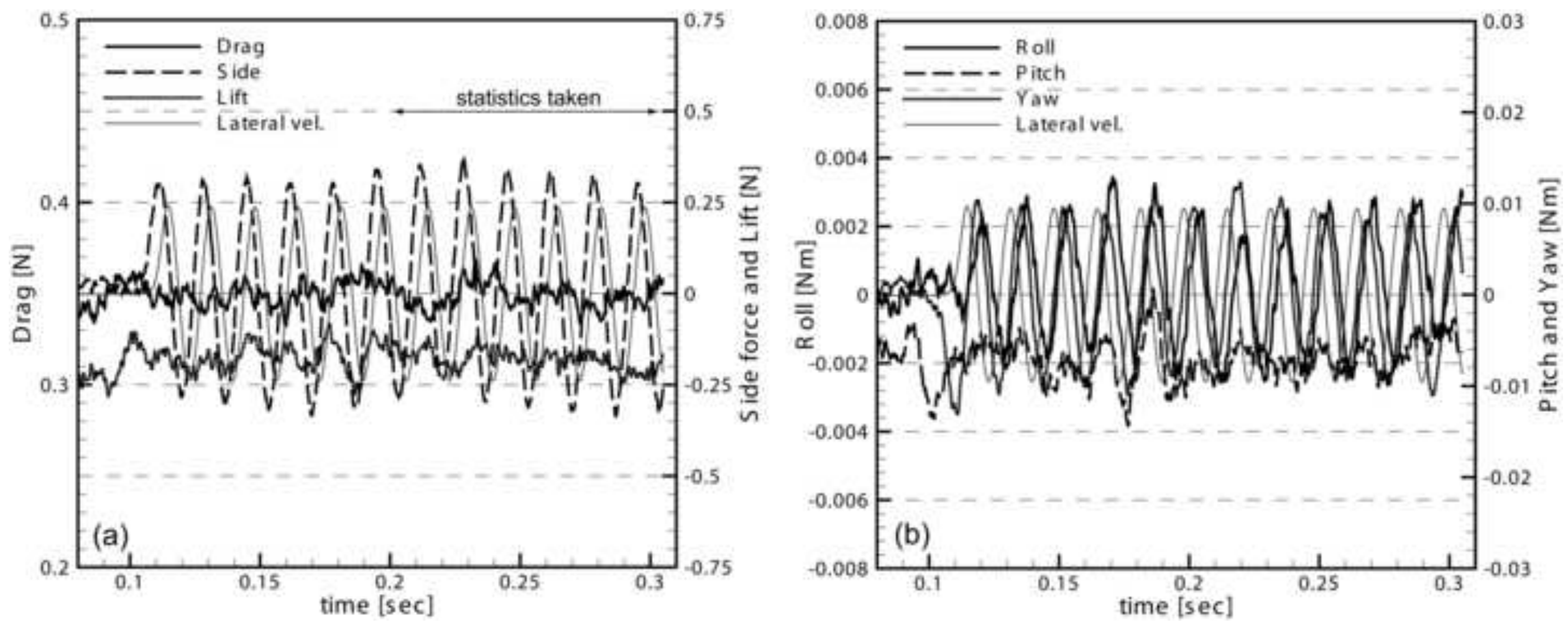

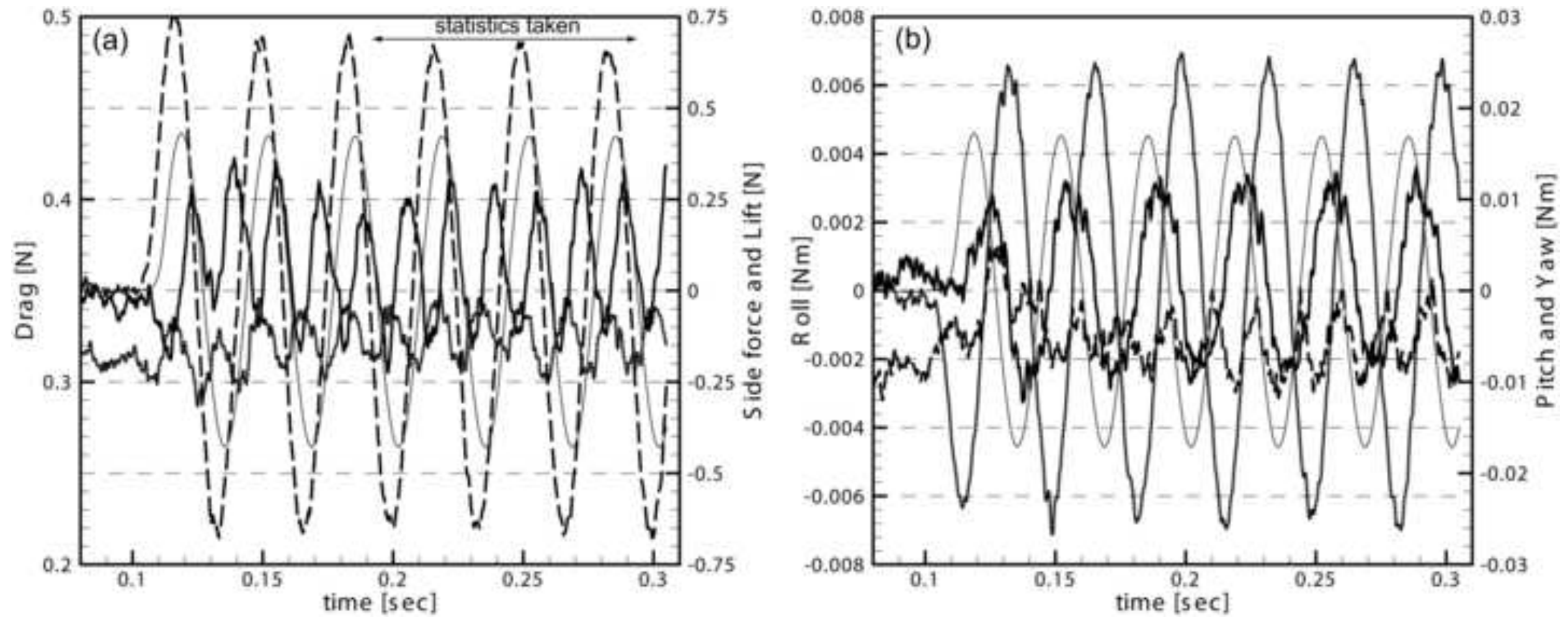
Click here to download high resolution image
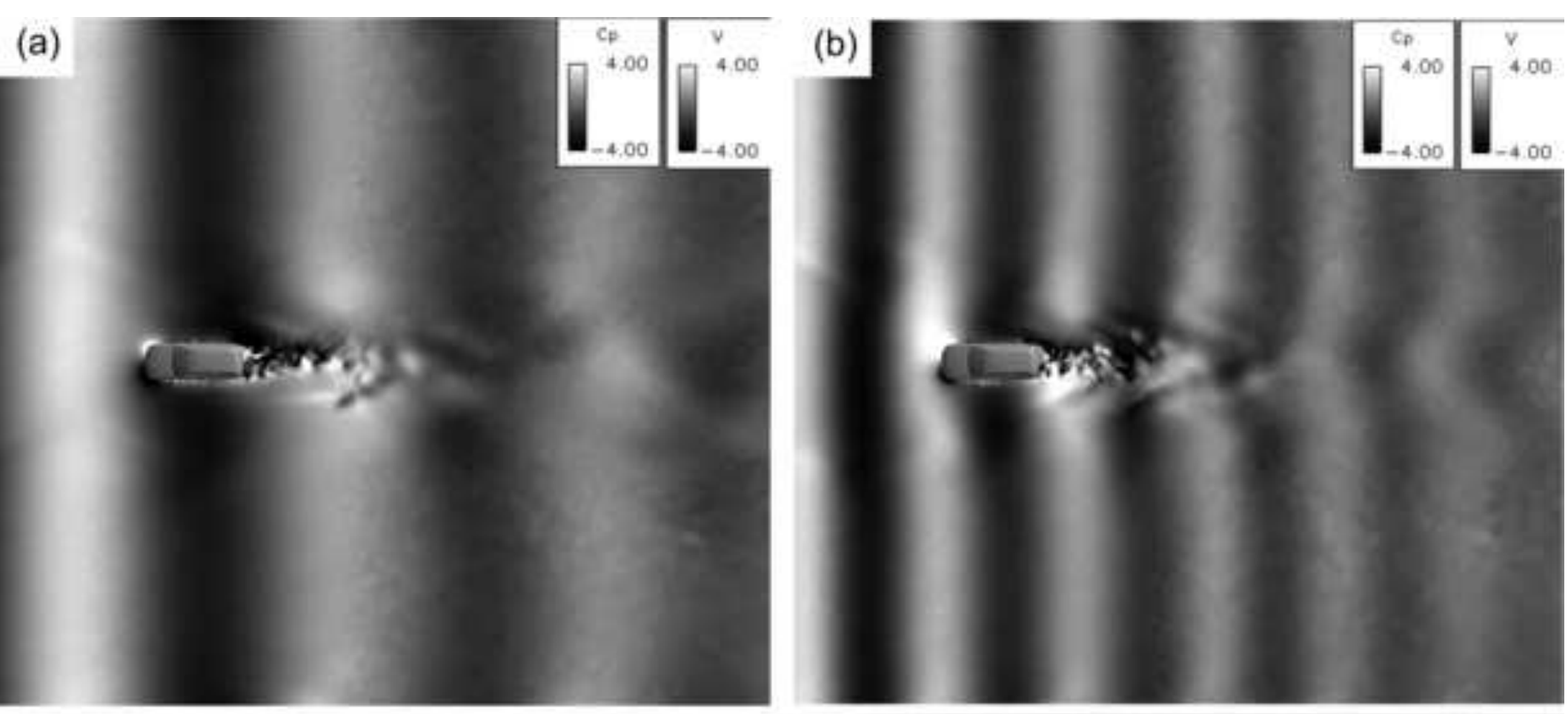

(c)

(d)
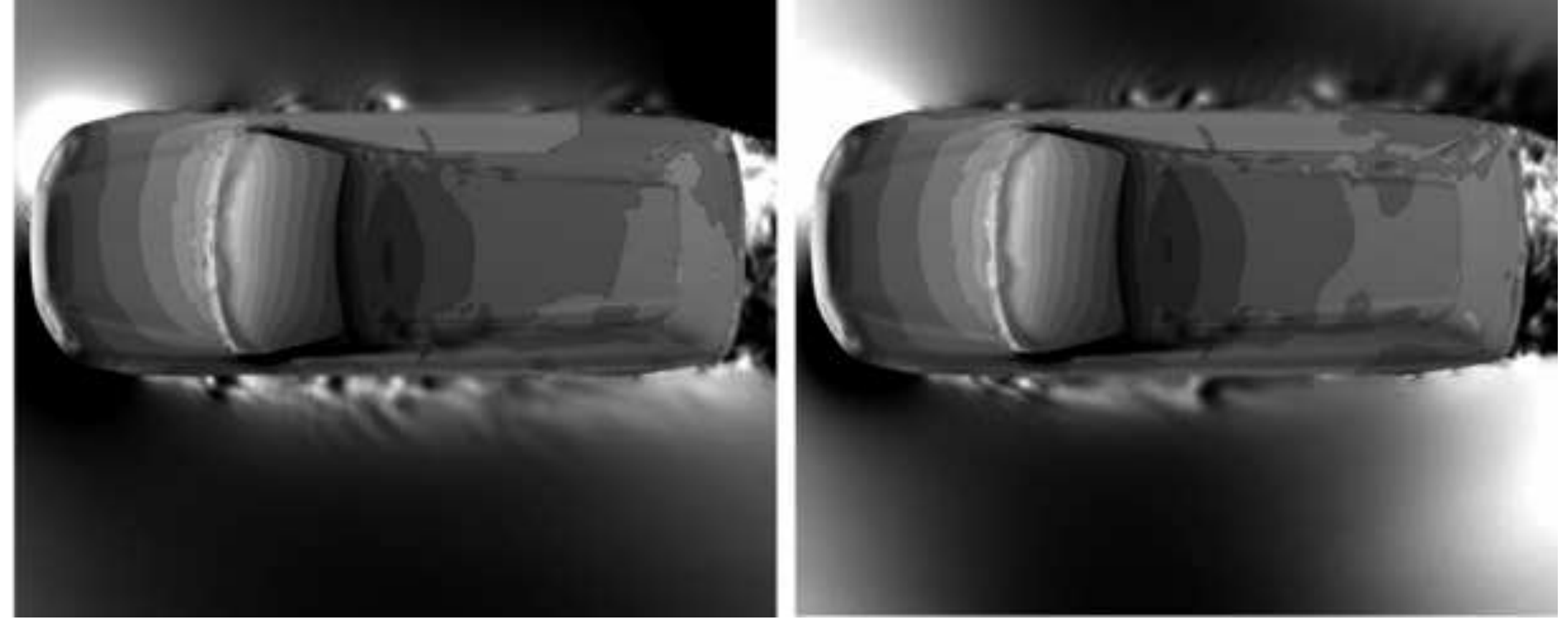

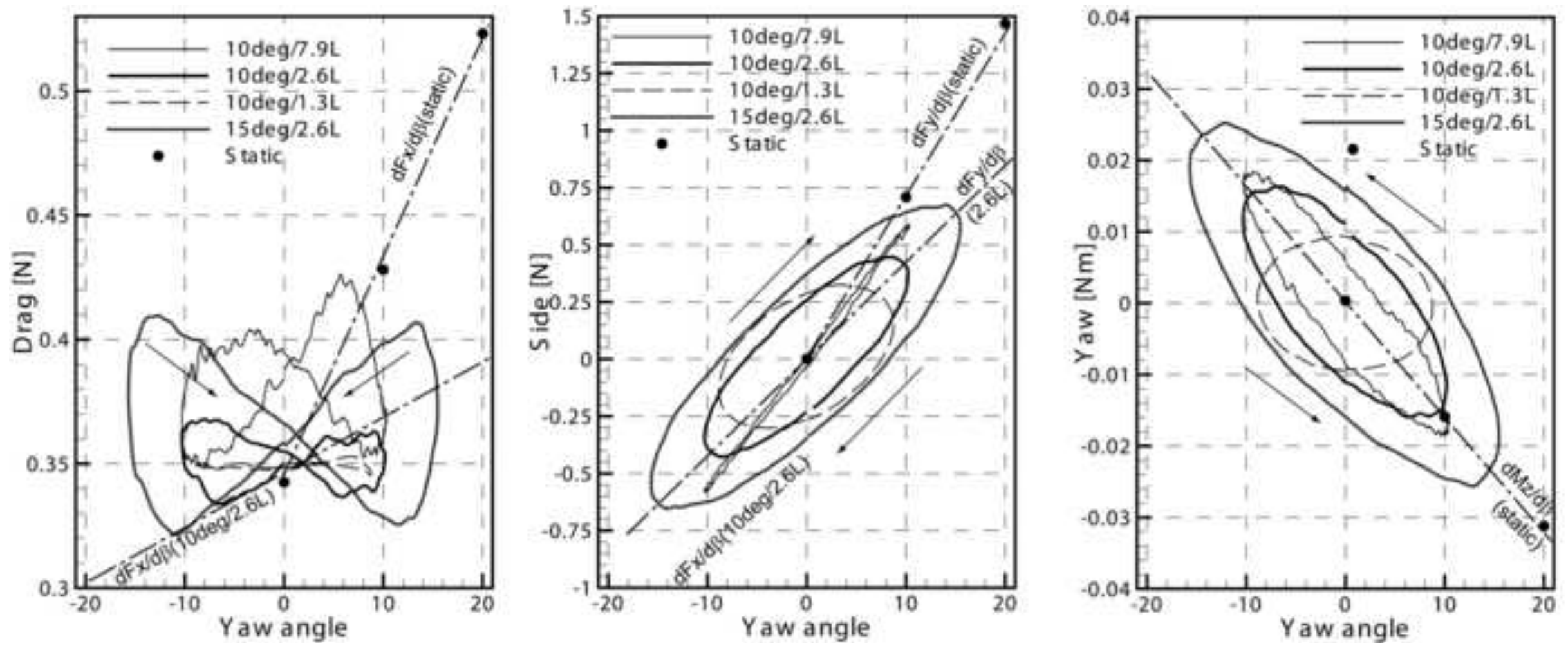

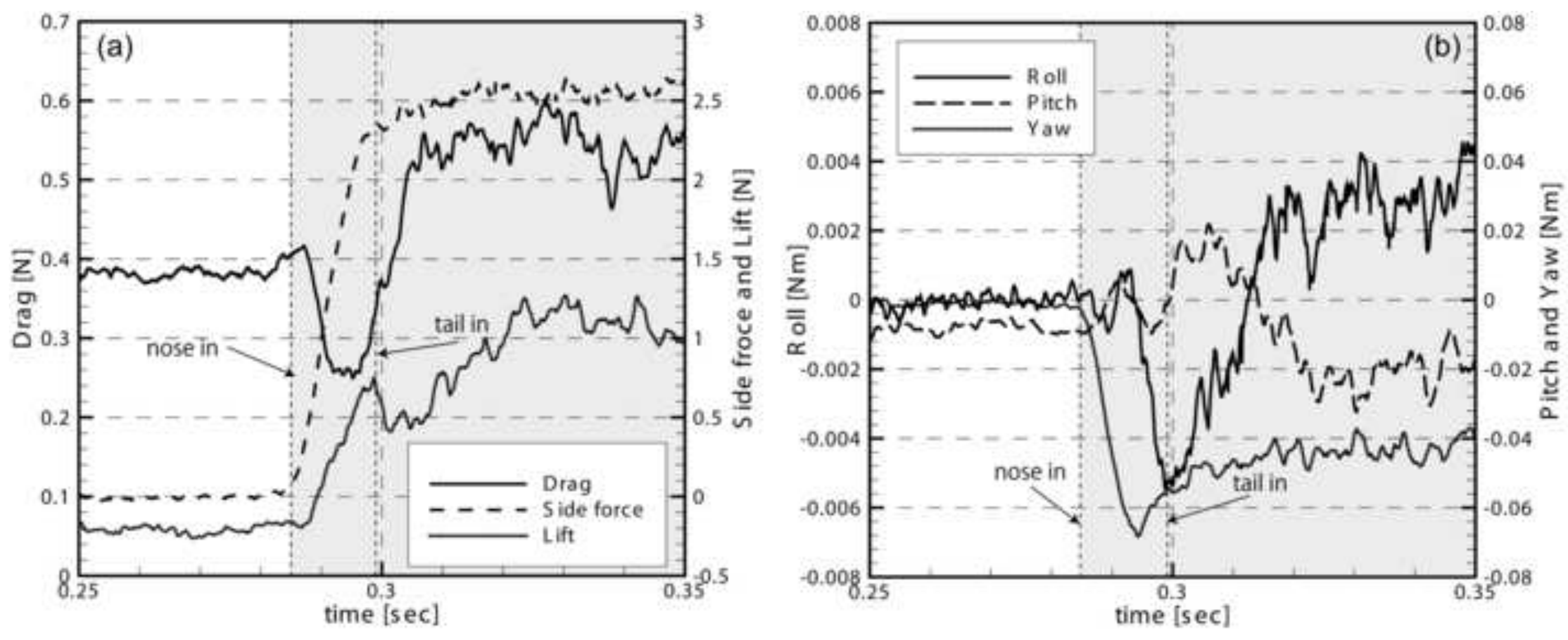
Click here to download high resolution image
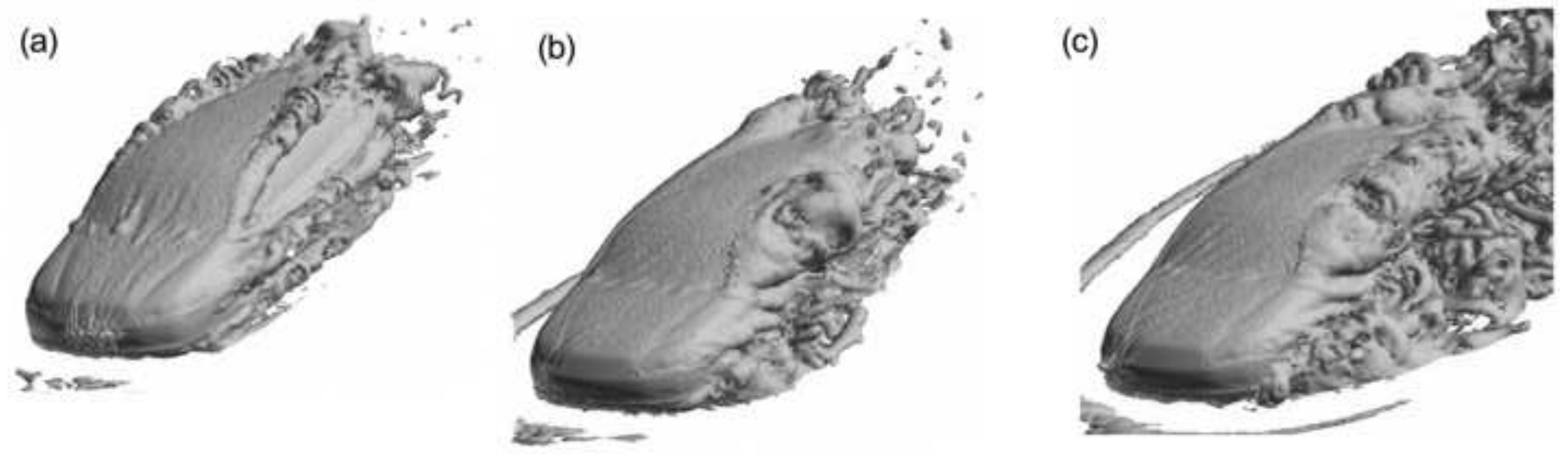

$$
\text { . }
$$


Figure

Click here to download high resolution image

$$
t=0.275 \mathrm{~s}
$$

leeward

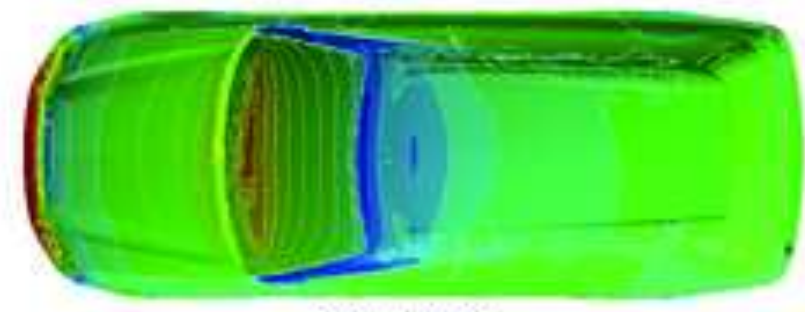

windward

$t=0.2925 \mathrm{~s}$

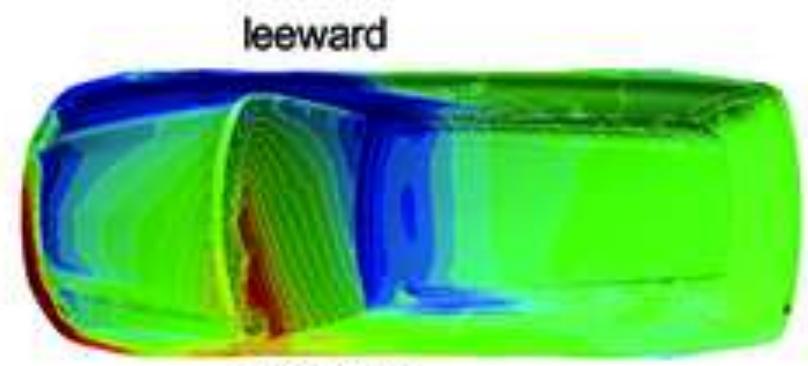

windward

\section{$t=0.2975 \mathrm{~s}$}

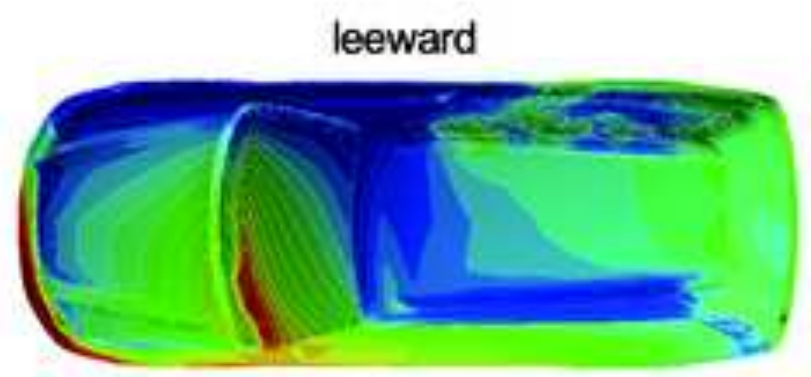

windward

$t=0.330 \mathrm{~s}$

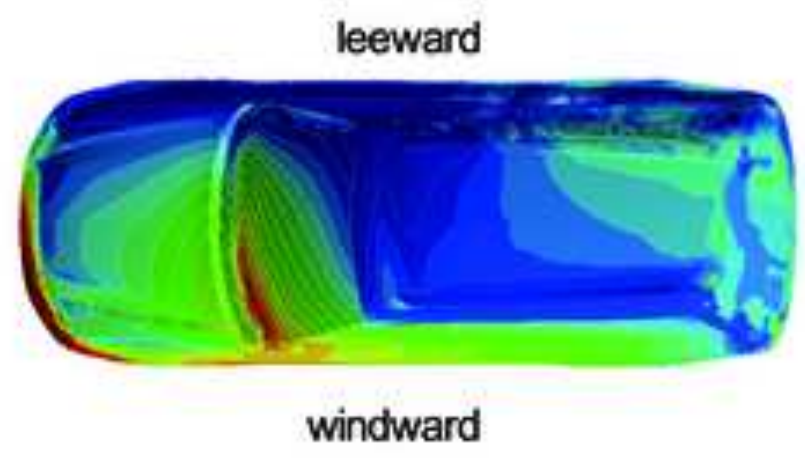

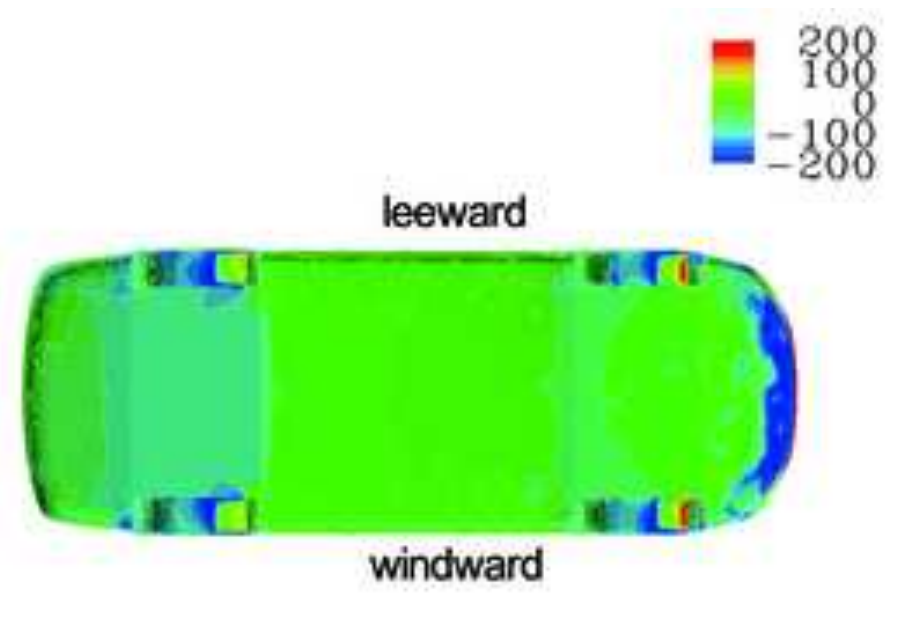
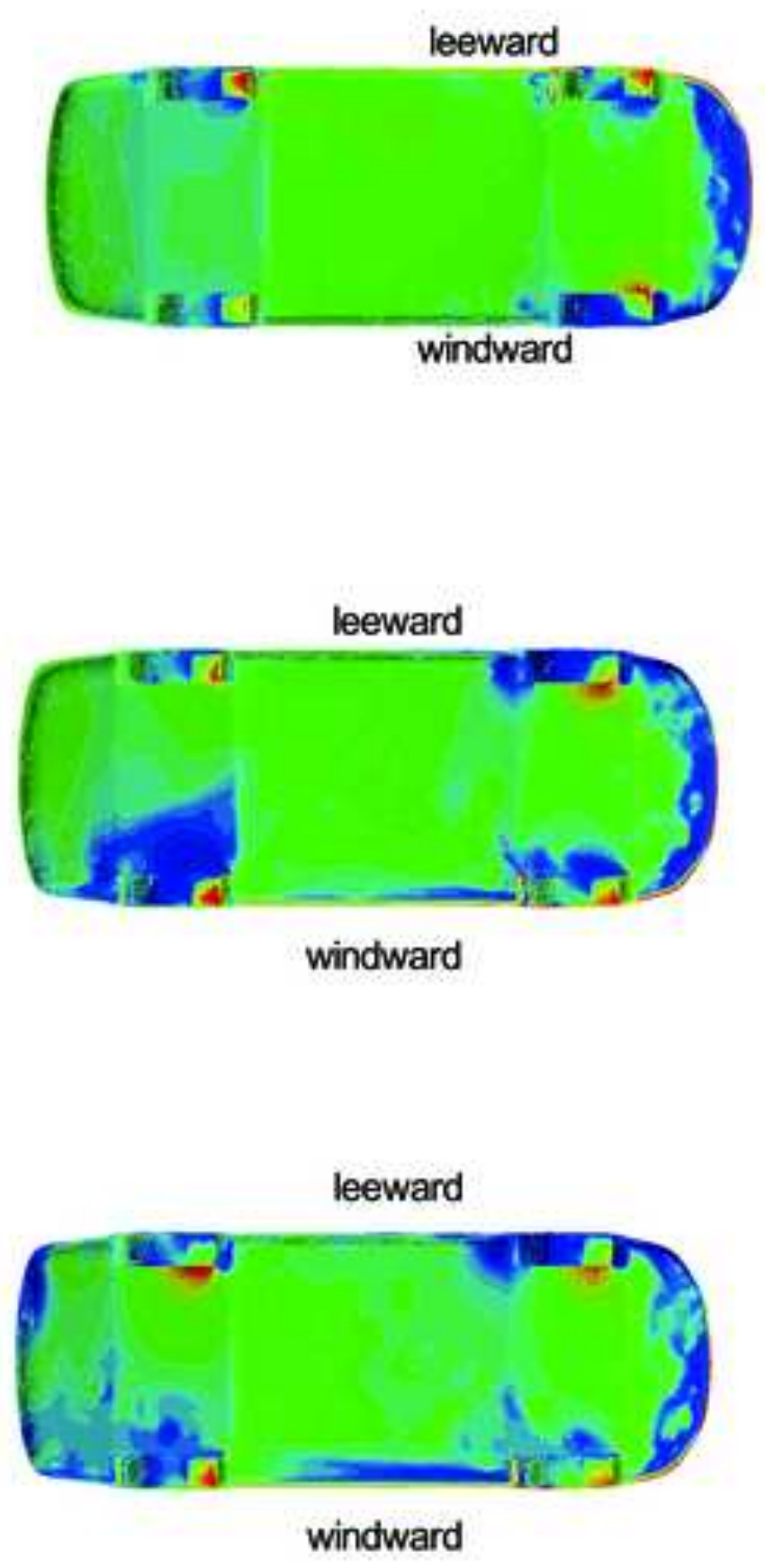